\title{
Increasing LPG production by adding volatile hydrocarbons to reduce import gap in Egypt
}

\author{
Ahmed M. Shahin ${ }^{1} \cdot$ Ayat O. Ghallab² $\cdot$ Ahmed Soliman ${ }^{2}$ \\ Received: 16 July 2020 / Accepted: 11 September 2020 / Published online: 27 September 2020 \\ (c) The Author(s) 2020
}

\begin{abstract}
Liquefied petroleum gas (LPG) becomes popular in the twentieth century as source of energy, since it is economically feasible to be produced, transported, sold and stored as a liquid fuel. LPG in Egypt is considered one of the most important domestic fuels. Egypt imports half of its LPG fuel demand. Many researches have been developed to increase the production of LPG in Egypt by increasing the productivity of the refineries. The objective of this study is to investigate the possibility of adding other relatively volatile hydrocarbons as ethane, $n$-pentane and pentanes' isomers (iso-pentane and neo-pentane) and/or utilizing relatively volatile oxi-hydrocarbons [mainly dimethyl ether (DME) or dimethyl propane (DMP)] to increase LPG production without affecting its specifications, in order to reduce the import gap of LPG in Egypt. The new LPG mixture is adjusted to meet the Egyptian specifications of LPG (2020). Due to ethane critical properties, it is recommended not to add ethane to LPG since the behavior of ethane cannot be predicted at $50{ }^{\circ} \mathrm{C}$ and will be separated inside the LPG bottle. In addition, it will necessitate the increase in LPG butane content. In summer, it is recommended to add i-C5 or 2,2DMP or a mixture of both to LPG (depending on the cost). In winter, it is recommended to add 2,2DMP or a mixture of 2,2DMP with i-C5 to LPG (depending on the cost). Adding DME to LPG with any percentage will decrease the heating value below the Egyptian heating value specifications (2020). Adding neo-pentane to LPG is more preferable than DME, since the heating value of neo-pentane is higher than that of DME. Also, the production cost of the neo-pentane is lower than that of DME.
\end{abstract}

Keywords Natural gas $\cdot$ Liquefied petroleum gas $\cdot$ Pentanes $\cdot$ Dimethyl ether $\cdot$ Hydrocarbons $\cdot$ Oxi-hydrocarbons

\section{Introduction}

Propane and butane are the main components of liquefied petroleum gas (LPG). They can also exist as individual components (pure propane or butane). The ratio of propane to butane in LPG depends on the final consumer, whether industrial or commercial use or for domestic purposes (Bilal and Said 2003; Martyr and Plint 2012).

Ayat O. Ghallab

ayatossama@hotmail.com

Ahmed M. Shahin

ahmed.shahin@shell.com

Ahmed Soliman

soliman101@gmail.com

1 Shell Egypt NV, Fifth Settlement, Road 90, New Cairo 11835, Egypt

2 Chemical Engineering Department, Faculty of Engineering, Cairo University, Giza 12613, Egypt
Generally, the production of LGP follows the agreement with consumers or follow the specifications fixed by the country about the composition (Liang et al. 2010). The specifications of LGP are based on the minimum vaporization rate, maximum vapor pressure and the limitation of corrosive components such as sulfur and water (Zakaria et al. 2006; Yaws 2015). Table 1 shows LPG specifications for the Egyptian market (Egyptian Organization for Standards and Quality).

Liquefied petroleum gas has become more popular, as it can be produced as a high-quality product. It is environmentally friendly and can be delivered to the customer using cylinder, pipeline or through bulk storage (Jamis and Sandoval 2002). LPG is economically feasible to be transported, produced, stored and sold as a liquid fuel (Stawczyk 2003). The main advantage of LPG is that its heating value is highly concentrated compared to other liquefied fuel (Johnson 1977). One cubic feet of liquefied propane can provide nearly $47 \%$ more heating value than the same quantity of liquefied methane (Clifford 1973). The main benefit also of 
Table 1 Egyptian LPG specifications (Egyptian Organization for Standards and Quality)

\begin{tabular}{|c|c|c|c|c|}
\hline \multirow[t]{2}{*}{ Test } & \multirow[t]{2}{*}{ Measurement unit } & \multirow[t]{2}{*}{ SPEC } & \multicolumn{2}{|c|}{ Test method } \\
\hline & & & ASTM-D & ES \\
\hline Relative density @60/60F & - & Report & 1657 & 1807 \\
\hline Vapor pressure @ $50{ }^{\circ} \mathrm{C}$ & $\mathrm{kg}_{\mathrm{f}} / \mathrm{cm}^{2}(\mathrm{G})$ & $\begin{array}{l}10 \text { (summer) } \\
11.5 \text { (spring and autumn) } \\
12.8 \text { (winter) }\end{array}$ & 1267 & 1285 \\
\hline $\begin{array}{l}\text { Volatility (temperature at which } 95 \text { vol\% of LPG sample } \\
\text { evaporate) }\end{array}$ & ${ }^{\circ} \mathrm{C}$ & $\begin{array}{l}17 \text { (summer) } \\
8 \text { (spring and autumn) } \\
4 \text { (winter) }\end{array}$ & 1837 & 1199 \\
\hline Copper strip corrosion @ $100{ }^{\circ} \mathrm{C}$ for 1 h (maximum) & - & No. 1 & 1838 & 419 \\
\hline Mercaptan sulfur & $\%$ Mass & $(0.003-0.008)$ & IP 272 & 1137 \\
\hline Hydrogen sulfide & & Nil & 2420 & 2517 \\
\hline Free water & & Nil & - & Visual \\
\hline Gross heating value & $\begin{array}{l}\mathrm{kcal} / \mathrm{kg} \\
\mathrm{mJ} / \mathrm{kg}\end{array}$ & $\begin{array}{l}11,800 \\
49.4\end{array}$ & 3588 & 2873 \\
\hline
\end{tabular}

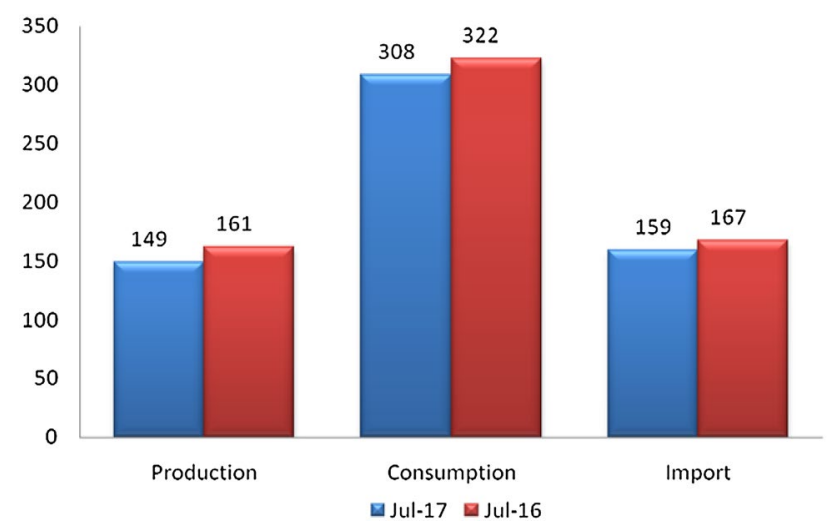

Fig. 1 LPG (in Mton) production, consumption and import in Egypt (Egyptian Central Agency for Public Mobilization and Statistics)

using LPG in such wide scale is that LPG is recognized as clean fuel (Diaz et al. 2000). Accordingly, the consumption of LPG is increasing and the code of practice is released to guarantee the safety using of LPG as a source of energy (Lemoff 1989).

The world production of LPG reached over $317 \mathrm{mn}$ tons/ year in 2018, while its consumption exceeds $313 \mathrm{mn}$ tons/ year (Statistical Review of Global LPG). In Africa, around $84 \%$ of LPG consumption is domestic, while in Asia pacific region this value was around 48\% (WLPGA Annual Report).

LPG in Egypt is considered one of the most important domestic fuels. In 2017, the Egyptian market consumed around 4.2 Mton of LPG. Figure 1 illustrates the Egyptian production, consumption and import of LPG in 2016 and 2017 (Egyptian Central Agency for Public Mobilization and Statistics). It is clear from the above figure that Egypt suffers from LPG shortage. Reducing this gap by exportation is an expensive solution, which may have negative economic impact. Unlike previous researches that aimed at reducing the import gap of LPG in Egypt by increasing LPG production from crude oil or natural gas, the novelty of this study is to increase the production rate of LPG by adding other relatively volatile hydrocarbons. Those hydrocarbons are ethane, $n$-pentane and pentanes' isomers (iso-pentane and neo-pentane) and/or relatively volatile oxi-hydrocarbons, mainly dimethyl ether. Although the composition of LPG will contain other hydrocarbons than propane and butane, the new LPG mixture is adjusted to meet the Egyptian specification of LPG.

\section{Literature review}

LPG is mainly produced from natural gas processing plants and refineries. Around $62 \%$ of LPG is produced from natural gas processing. Separation of natural gas is accomplished by using two-phase separators as slug catcher and or threephase separator to separate gas, condensate and water. The natural gas is then dehydrated to remove water, to avoid any hydrate formation during deep cooling of natural gas. Then the natural gas is further treated to recover hydrocarbons as ethane plus components, known as natural gas liquids (NGL). Natural gas liquids can be recovered using typical refrigeration, or by using Joule Thomson valve in addition to mechanical refrigeration or by using turbo expanders (GPSA 2020).

Many researches had also been developed to increase the production of LPG either from crude oil or natural gas. Recovery of LPG from natural gas could be enhanced by applying chemical absorption. The feed gas is introduced into slug catcher to separate the inlet feed into gas, condensate and water mixture. The slug catcher liquid stream is separated into condensate and water in threephase separator. Condensate is further stabilized to remove 
dissolved gasses. The stabilized condensate is provided into de-butanizer tower to remove the LPG from the top of the tower, and remaining condensate is stored in condensate storage tanks. Another LPG absorption tower has been added to remove LPG from the slug catcher overhead gas with cooled condensate (Liu et al. 2015). The performance of LPG recovery units could be improved by selecting the optimal operating conditions (Bahmani et al. 2017).

In Egypt, many researches have been performed to increase the production of LPG that is extracted from natural gas. In El-Wastani Petroleum Company in Egypt, they increased the recovery of butane from natural gas from 80 to $99 \%$ and produced commercial propane with recovery of propane $90 \%$ by further distillation of the separated NGL that was extracted from natural gas. Totally, LPG production has increased from 164.8 to 274.4 ton/day (Ammar and Khalifa 2013). Also, there has been a proposed modification by Salam Gas Plant (Khalda Petroleum Company, Egypt) to recover LPG from NGL by adding de-ethanizer and debutanizer towers to the plant to save 50 ton/day of LPG (Bhran et al. 2015).

LPG produced can also be exploited in a better way by minimizing the residue remained in the LPG bottles. To do so, most of the researches tried to maximize the amount of heat transferred from surrounding to LPG bottle by different methods such as hollow tubes application, warm water, changing LPG bottle diameter, adding absorbent material, spiral coil and coating agent (Zakaria and Mustafa 2011; Wooley 1980). The drawback of this method is that the total amount of LPG initially filling the cylinder is reduced. Also, if LPG discharge rate from the cylinder is high, the liquid temperature is reduced rapidly up to freezing point (Chang and Reid 1982). Another option is using capillary tube to suck up the residue or the heavy liquid from the bottom of the LPG cylinder. This can be applied when the LPG is stored under pressure, although it is a very expensive solution (Yue 1999).

Like LPG, dimethyl ether (DME) is gaseous at normal temperature and pressure, but changes to a liquid when subjected to modest pressure or cooling. This easy liquefaction makes DME easy to transport and store. This and other properties, including a high oxygen content, lack of sulfur or other noxious compounds and ultraclean combustion make DME or a mixture of DME and LPG a promising solution in the mixture of clean renewable and low-carbon fuels under consideration worldwide (Anggarania et al. 2014).

\section{Methodology}

The objective of this study is to reduce the import gap of LPG in Egypt by increasing the production rate of LPG by utilizing other relatively volatile hydrocarbons as ethane, $n$-pentane and pentanes' isomers (iso-pentane and neo-pentane) and/or utilizing relatively volatile oxi-hydrocarbons mainly dimethyl ether (DME). Although the produced LPG contains other hydrocarbons than propane and butane, the new LPG mixture is adjusted to meet the Egyptian specifications of LPG. This study will also cover the optimum process design to produce one of the most promising volatile hydrocarbons, namely neo-pentane.

The methodology can be summarized in the following steps:

1. Steady-state and dynamic HYSYS models were built to simulate LPG weathering test (ASTM D-1837) to determine the weathering of LPG sample. Figures 2 and 3 illustrate the steady-state and dynamic HYSYS model for LPG weathering.

2. Simulation models were validated by comparing the simulation output with ASTM D-1837 experiment data
Fig. 2 Steady-state model for weathering of LPG

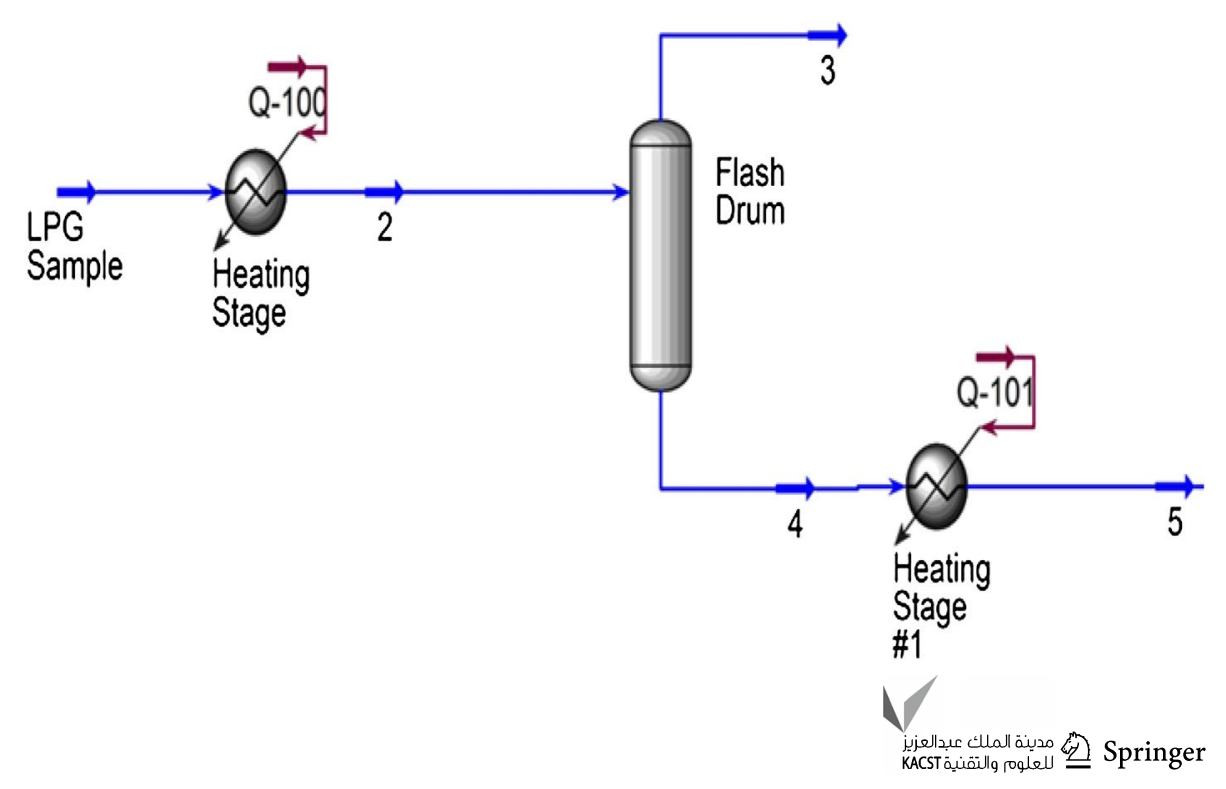


Fig. 3 Dynamic model for weathering of LPG

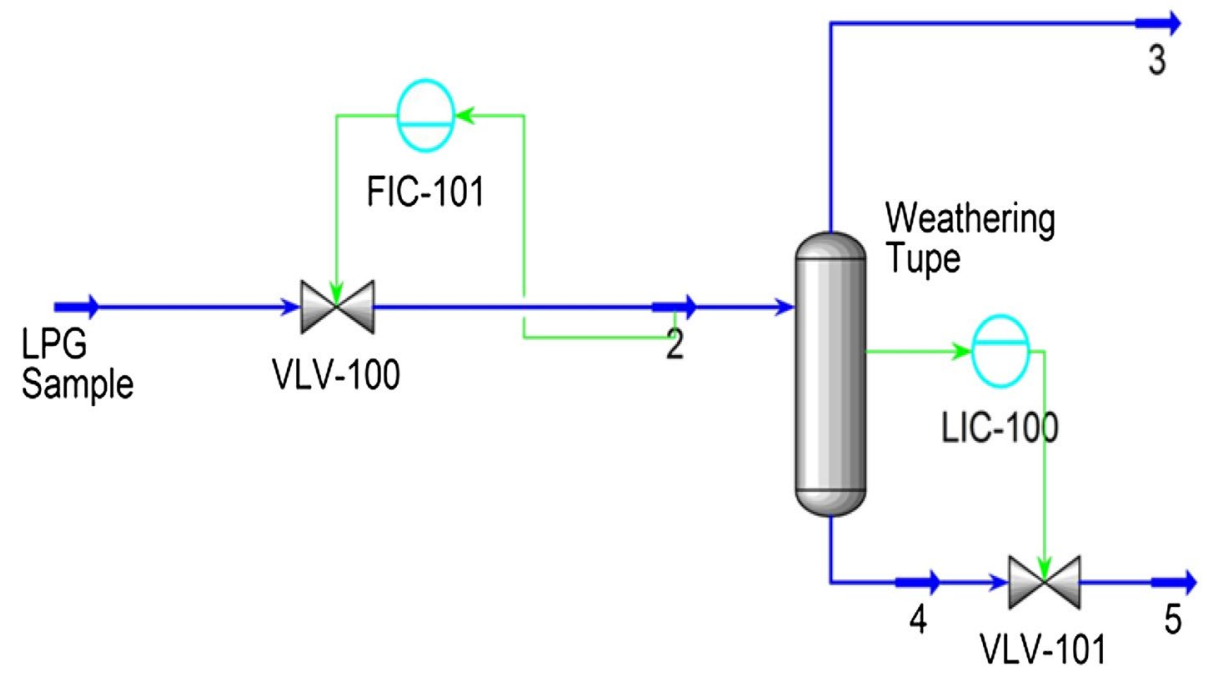

Table 2 LPG components price [1-8]

\begin{tabular}{ll}
\hline Component & US\$/Mton \\
\hline Ethane & 208 \\
Propane & 500 \\
i-C4 & 490 \\
n-C4 & 440 \\
2,2DMP & 606.3 \\
i-C5 & 485 \\
n-C5 & 485 \\
DME & 1000 \\
\hline
\end{tabular}

Fig. 4 Comparison of simulation models output with ASTM D-1837

that was collected from different refineries, as illustrated in Fig. 4.

3. Relative volatile components as ethane, normal pentane, iso-pentane, neo-pentane and DME were added separately to LPG. The volatility of new LPG mixture has been calculated by using the dynamic model of LPG weathering.

4. Various mixtures have been tested and the mixtures that meet weathering and vapor pressure specifications have been selected, and their cost and heating value have been calculated. Table 2 shows LPG components price utilized in this research [1-8].

5. The effect of adding new components to LPG heating value and price has been determined and compared to select the applicable blends. Also the limitations of adding the new components were studied, according to the residue amount.

6. Since the neo-pentane gives the optimum results but is not produced in industrial scale, a process scheme for neo-pentane production has been provided.

\section{Simulation}

The main specifications of LPG are vapor pressure, volatility and heating value. The vapor pressure and heating value have been calculated using Aspen 7.3 by using Peng-Robinson as thermodynamic equation of state, and in case of adding dimethyl ether, the SRU-TWU was used as thermodynamic package. Vapor pressure of LPG mixture has been calculated at $50{ }^{\circ} \mathrm{C}$. The composition of each proposed LPG mixture has been adjusted to get the specifications' vapor pressure value, gauge $\left(10 \mathrm{~kg}_{\mathrm{f}} / \mathrm{cm}^{2}\right.$ in summer and $12.8 \mathrm{~kg}_{\mathrm{f}} / \mathrm{cm}^{2}$ in winter). Accordingly, the heating value $(\mathrm{kcal} / \mathrm{kg})$ and residue have been calculated.

The LPG volatility or residue has been calculated by two different simulation models. The weathering test results of LPG have been collected from different refineries in different seasons (summer and winter) and compared with the output result from volatility models. Table 3 shows the collected data of LPG weathering experiments.

Aspen HYSYS process simulation software (version 7.3) has been used to provide two simulation models (steady-state and dynamic models) with Peng-Robinson package to simulate weathering experiment (ASTM 
Table 3 Collected data of LPG weathering experiment

\begin{tabular}{lllll}
\hline Composition & Case 1 & Case 2 & Case 3 & Case 4 \\
\hline $\mathrm{C} 2, \mathrm{~mol} \%$ & 0 & 5.7 & 4.6 & 5.8 \\
$\mathrm{C} 3, \mathrm{~mol} \%$ & 2.48 & 29.6 & 24 & 31.3 \\
$\mathrm{i}-\mathrm{C} 4, \mathrm{~mol} \%$ & 33.65 & 22.1 & 14.5 & 21.4 \\
$\mathrm{n}-\mathrm{C} 4, \mathrm{~mol} \%$ & 58.99 & 38.2 & 46.7 & 38.4 \\
$\mathrm{i}-\mathrm{C} 5, \mathrm{~mol} \%$ & 2.16 & 1.2 & 3.05 & 0.65 \\
$\mathrm{n}-\mathrm{C} 5, \mathrm{~mol} \%$ & 0.17 & 1.2 & 3.05 & 0.65 \\
$\mathrm{H}_{2} \mathrm{~S}, \mathrm{~mol} \%$ & 0 & 2 & 4.1 & 1.8 \\
1-Butene, mol\% & 2.55 & 0 & 0 & 0 \\
ASTM D1837, ${ }^{\circ} \mathrm{C}$ & 1.4 & 4 & 13 & 1 \\
\hline
\end{tabular}

D-1837). Data were validated by comparing with the collected data shown in Table 3.

\section{Quasi steady-state model}

The weathering experiment was performed by collecting the liquefied sample of LPG in the weathering tube and allowing the sample to "weather" evaporate at ambient pressure. The temperature when $5 \mathrm{ml}$ of liquid test portion remains was observed.

In the steady-state model, LPG sample stream pressure is $1 \mathrm{~atm}$. and the vapor fraction is 0 . The sample is then heated gradually with constant temperature difference (dT) and after each heating stage the remaining liquid of the sample was introduced into flash drum to remove the flashed vapor. The stage (heating + flashing) was repeated until the remaining liquid of the sample becomes $5 \%$ of the inlet volumetric flow rate.

The main parameter that controls the series of heating/ flashing steps was the temperature difference through each heater. dT in each heating stage has been changed from 0.05 to 1 to select the realistic value of dT that gives residual value as per experiment.

The model contains the following items:

1. The heater: is mainly to evaporate the sample gradually.

2. The flash knock-out drum: to separate the flashed gas and the remaining liquid.

The remaining liquid was further heated/flashed until its volumetric flow rate become $5 \%$ of the inlet flow. The temperature of this $5 \%$ liquid is the weathering temperature. Figure 2 illustrates two heating stage with flash knock-out drum between each heating stage.

\section{Dynamic model}

In the dynamic model, ASTM D1837 was simulated as vessel with inlet stream controlled by a flow control valve, to fill the vessel with LPG sample. The outlet streams are the overhead vapor, to allow sample to be evaporated, and bottom liquid stream to control the level inside the vessel as shown in Fig. 3 .

There are two modes in the dynamic model, the filling mode and the evaporation mode. First, the vessel which represent the weathering tube is filled up to $80 \%$ and controlled by the inlet flow controller and the level controller. Then, the sample is allowed to flash by closing the inlet control valve and the outlet bottom valve on the liquid outlet and active the heat loss model on sample mode.

The procedure to get the weathering temperature by the dynamic model was performed as follows:

1. The composition of LPG sample stream at atmospheric pressure and zero vapor fraction was fed. Accordingly, HYSYS will calculate the bubble point temperature.

2. The dynamic model after filling the weathering tube was run by setting the flow and level controllers on auto mode with $0.5 \mathrm{kgmol} / \mathrm{h}$ and $80 \%$ as set points, respectively.

3. Then the flow and level controllers were changed from auto mode to manual mode with set point 0 and the model was run.

4. The level of the vessel at $17{ }^{\circ} \mathrm{C}$ in summer of at $4{ }^{\circ} \mathrm{C}$ in winter was recorded. This value represents the residual of LPG.

In ASTM D1837 the sample was collected at atmospheric pressure and in the liquid phase and was allowed to flash to atmosphere, which means that in the dynamic model, the LPG sample stream pressure is $1 \mathrm{~atm}$. and the vapor fraction is zero and the heat transfer module that used is simple heat transfer with air. The main parameter in the dynamic model is the heat transfer area that required evaporating the sample. The volume of the sample is $100 \mathrm{ml}$, and the heat transfer area of the weathering tube is $171.2 \mathrm{~cm}^{2}$.

In the dynamic model, the following items have been utilized to simulate the weathering experiment.

1. Flash knock-out drum: representing the weathering tube. The dynamic data for the weathering tube shown in Table 4 are as follows:

2. Inlet flow controller: to fill the weathering tube.

Table 5 shows the flow controller set point for dynamic model.

3. Level flow controller: to observe the level inside the weathering tube during evaporation.

Table 6 shows level flow controller set point for dynamic model. 
Table 4 Dynamic data for the weathering tube

\begin{tabular}{ll}
\hline Vessel volume $(\mathrm{ml})$ & 125 \\
Vessel diameter $(\mathrm{mm})$ & 24 \\
Vessel length $(\mathrm{mm})$ & 276 \\
Overall heat transfer area $\left(\mathrm{mm}^{2}\right)$ & 20,833 \\
Start liquid level \% & 80 \\
$5 \%$ Equivalent liquid level & $4 \%$ \\
Ambient temperature $\left({ }^{\circ} \mathrm{C}\right)$ & 25 \\
Overall heat transfer coefficient of air $\left(\mathrm{kJ} / \mathrm{h} \mathrm{m}^{2}{ }^{\circ} \mathrm{C}\right)$ & 54 \\
\hline
\end{tabular}

Table 5 Flow controller set point for dynamic model

\begin{tabular}{lc}
\hline Process set point & Filling mood: \\
& $0.5 \mathrm{~kg} \mathrm{~mol} / \mathrm{h}$ \\
& Evaporation \\
& mood: $0 \mathrm{~kg}$ \\
& $\mathrm{~mol} / \mathrm{h}$ \\
Minimum process value & $0 \mathrm{~kg} \mathrm{~mol} / \mathrm{h}$ \\
Maximum process value & $1 \mathrm{~kg} \mathrm{~mol} / \mathrm{h}$ \\
\hline
\end{tabular}

Table 6 Level flow controller set point for dynamic model

\begin{tabular}{ll}
\hline Initial set point (filling stage) & $80 \%$ \\
Minimum process value & $0 \%$ \\
Maximum process value & $100 \%$ \\
\hline
\end{tabular}

Table 7 LPG residue by steady-state and dynamic models compared with the residue of LPG by ASTM D1837 test

\begin{tabular}{lllll}
\hline Test, ${ }^{\circ} \mathrm{C}$ & Sample 1 & Sample 2 & Sample 3 & Sample 4 \\
\hline $\begin{array}{l}\text { ASTM D-1837 } \\
\begin{array}{l}\text { Steady-state } \\
\quad \text { simulation model }\end{array}\end{array}$ & 1 & 1.4 & 4 & 13 \\
$\quad \begin{array}{l}\mathrm{dT}=0.12 \\
\text { Dynamic model }\end{array}$ & 0.81 & 1.452 & 3.7 & 13 \\
\hline
\end{tabular}

To validate the models, Table 7 shows the LPG residue by steady-state and dynamic models compared with the residue of LPG by ASTM D1837 test.

\section{Results and discussion}

\section{Effect of adding ethane to LPG}

Ethane has higher vapor pressure than LPG components. So, to maintain the LPG vapor pressure as required, adding ethane to LPG necessitates decreasing the propane content, while the butane content has to be increased.

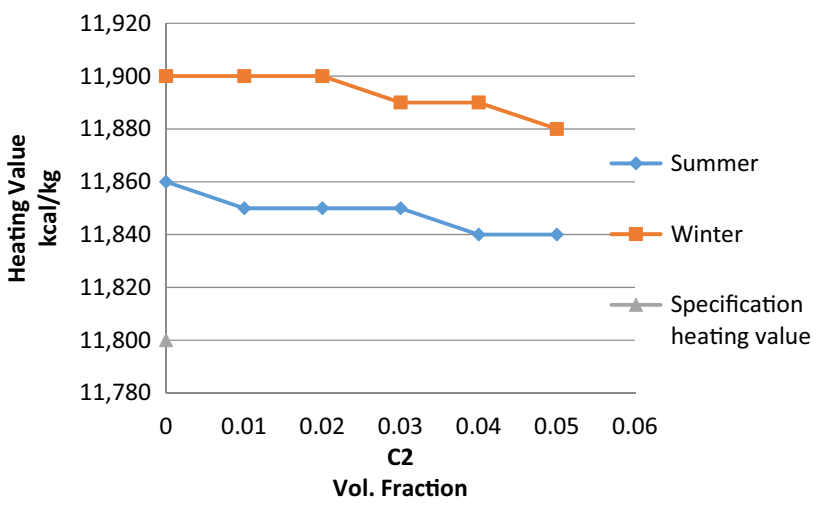

Fig. 5 Effect of adding ethane on LPG heating value

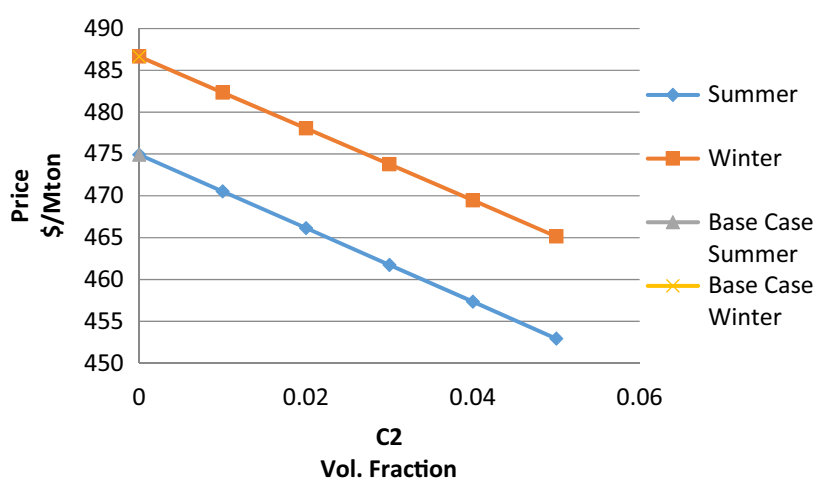

Fig. 6 Effect of adding ethane on LPG price

The heating value of LPG due to adding ethane does not dramatically decrease as shown in Fig. 5. The heating value of LPG after increasing ethane content is still higher than the specified heating value $(11,800 \mathrm{kcal} / \mathrm{kg})$.

The residue of LPG after adding ethane is zero percentage. This means that all LPG mixtures containing ethane will be vaporized from LPG bottle.

Adding ethane to LPG mixture will affect the butane and propane as per the following values:

- Summer case propane saving $=(0.460631-0.2516) /$ $0.460631 * 100=45 \%$.

- Winter case propane saving $=(0.69175-0.4825)$ / $0.69175 * 100=30 \%$.

- Summer case butane increase $=(0.6984-0.5395) / 0.539$ $5 * 100=29.5 \%$.

- Winter case butane increase $=(0.4675-0.30825) / 0.308$ $25 * 100=51 \%$.

Figure 6 shows the effect of adding ethane to LPG price. Increasing LPG ethane content decreases the LPG price.

The Egyptian specifications of LPG instructed to limit ethane content to be $5 \mathrm{vol} \%$ of LPG, due to the ethane 


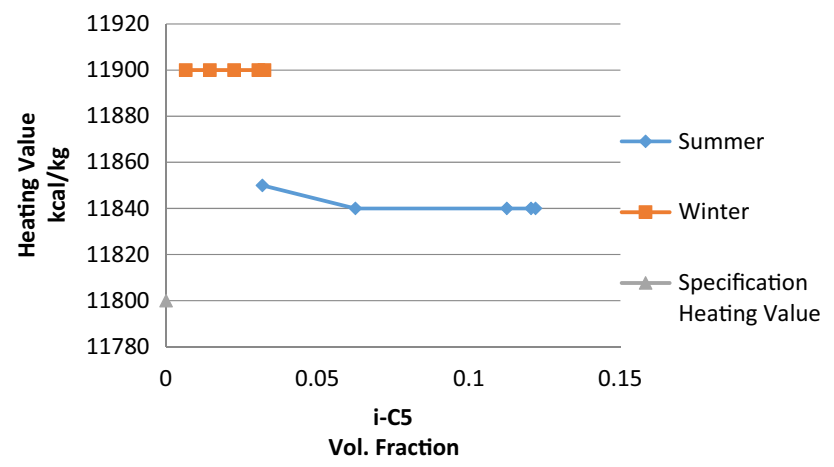

Fig. 7 Effect of adding i-C5 on LPG heating value

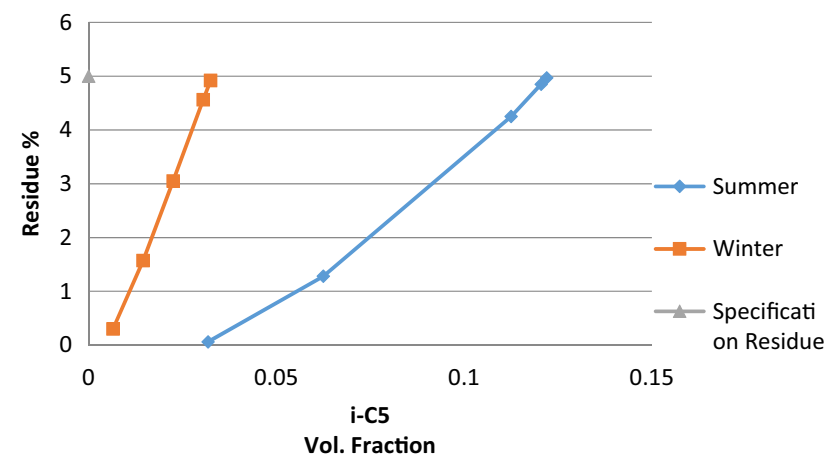

Fig. 8 Limitation of adding i-C5 to LPG

critical conditions $\left(T_{\mathrm{c}}=32.28{ }^{\circ} \mathrm{C}, P_{\mathrm{c}}=49 \mathrm{~kg}_{\mathrm{f}} / \mathrm{cm}^{2}\right)$. The behavior of ethane cannot be predicted at $50{ }^{\circ} \mathrm{C}$ and will be separated inside the LPG bottle. It will not form phase equilibrium with LPG contents. Accordingly, ethane content has to be minimized or not preferred in LPG.

\section{Effect of adding iso-pentane (i-C5) to LPG}

Adding i-C5 to LPG content is adjusted to get the vapor pressure value of LPG specifications and then the other specifications as LPG residue is measured/recorded from HYSYS dynamic model.

Iso-pentane has higher vapor pressure, so to maintain the LPG vapor pressure as required, the propane content has to be slightly increased, while the butane content has to be decreased.

The heating value of LPG by adding i-C5 is more than the specifications heating value $(11,800 \mathrm{kcal} / \mathrm{kg})$, as shown in Fig. 7.

Although i-C5 increases the heating value and requires the decrease in butane content, the limitation to add i-C5 to LPG is due to residue. Higher LPG i-C5 content increases LPG residue. Thus, to meet the LPG specifications, the maximum content of i-C5 inside LPG mixture has to be $12 \mathrm{vol} \%$ in summer and 3.3 vol\% in winter case as shown in Fig. 8.

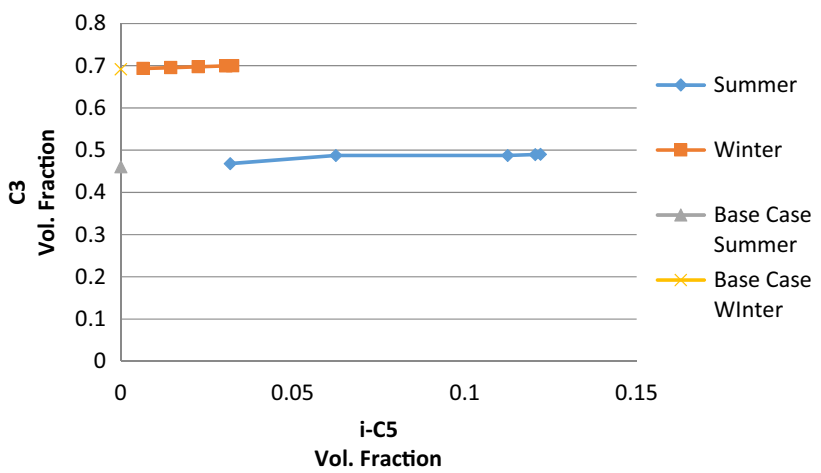

Fig. 9 Effect of adding i-C5 on LPG propane content

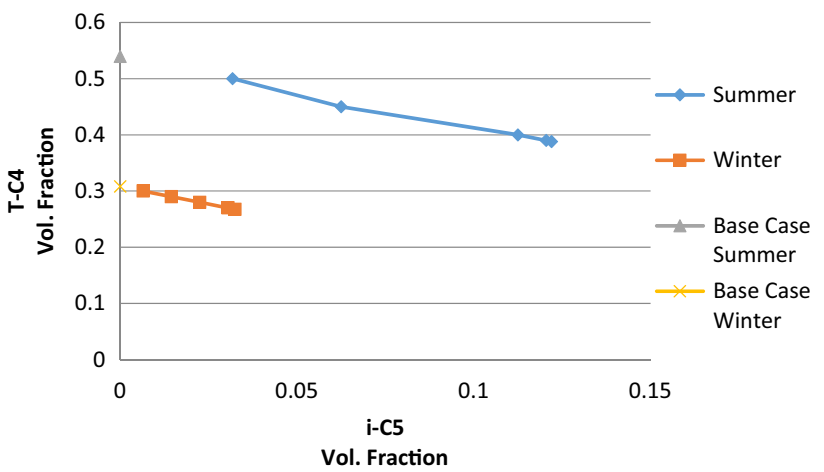

Fig. 10 Effect of adding i-C5 on LPG T-C4 content

Propane and butane will be affected by adding i-C5 as per the following values and Figs. 9 and 10:

- Summer case propane increase $=(0.49-0.460631) / 0.46$ $0631 * 100=6.5 \%$

- Winter case propane increase $=(0.7-0.69175) / 0.69175$ $* 100=1.1 \%$

- Summer case butane Saving $=(0.5395-0.388) /$ $0.5395 * 100=28 \%$.

- Winter case butane Saving $=(0.30825-0.26) /$ $0.30825 * 100=13 \%$.

Figure 11 illustrates the effect of adding i-C5 on LPG price. In case of adding i-C5 to LPG, the LPG price increases by $0.25 \%$ in winter case and by $1.1 \%$ in summer case.

\section{Effect of adding 2,2 dimethyl propane (2,2DMP) or neo-pentane to LPG}

Adding 2,2DMP to LPG is adjusted to get the vapor pressure value of LPG specifications and then the other specifications 


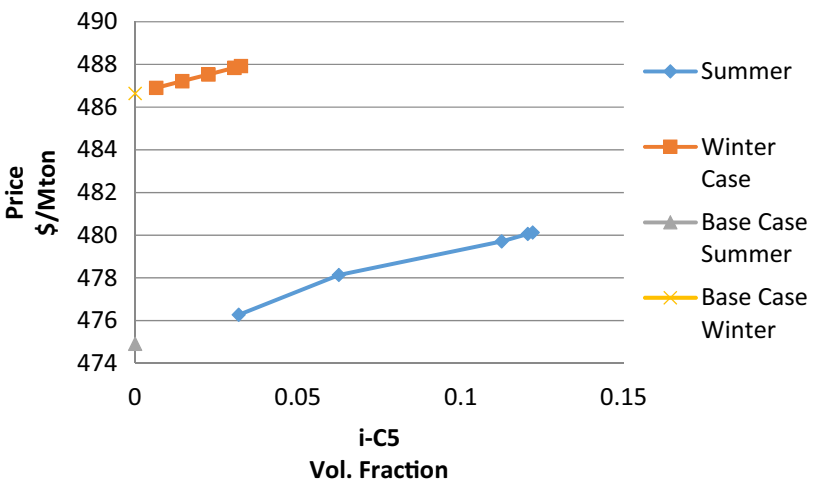

Fig. 11 Effect of adding i-C5 on LPG price

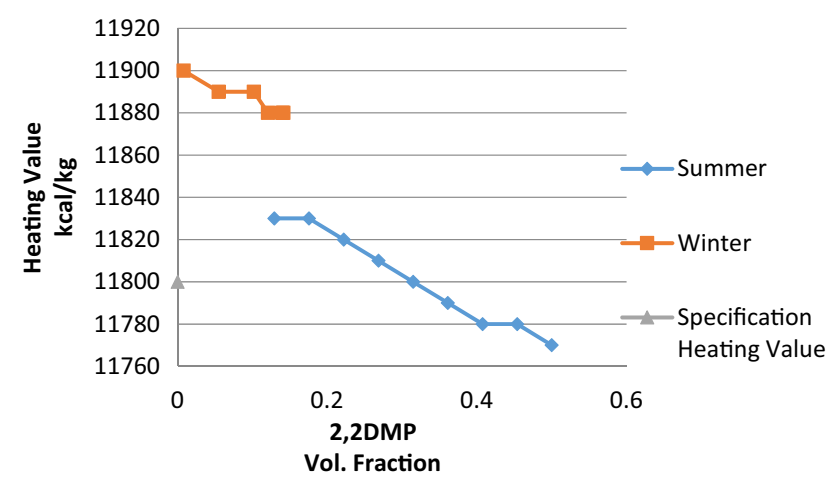

Fig. 12 Effect of adding 2,2DMP on LPG heating value

as LPG residue is measured/recorded from HYSYS dynamic model.

To maintain the LPG vapor pressure as required, adding 2,2DMP to LPG necessitates the decrease in butane content and requires the slight increase in the propane content.

In winter, the heating value of LPG is more than the specifications $(11,800 \mathrm{kcal} / \mathrm{kg})$ at any $2,2 \mathrm{DMP}$ content; meanwhile, there is a limitation to add 2,2DMP to LPG in summer to keep the heating value within acceptable range. Figure 12 shows the limitation of adding 2,2DMP (31.5 vol\%) to LPG.

There is no residue limitation to add 2,2DMP in summer LPG as shown in Fig. 13, but 2,2DMP could be added by maximum 14.8 vol. \% during winter.

Figure 14 illustrates the effect of adding 2,2DMP to LPG on LPG price. LPG price increases by $4.4 \%$ in winter and by $16.5 \%$ in summer case.

Propane and butane will be affected by adding 2,2DMP to LPG as per the following values and Figs. 15 and 16:

- Summer case propane increase $=(0.5-0.460631) / 0.460$ $631 * 100=8.6 \%$

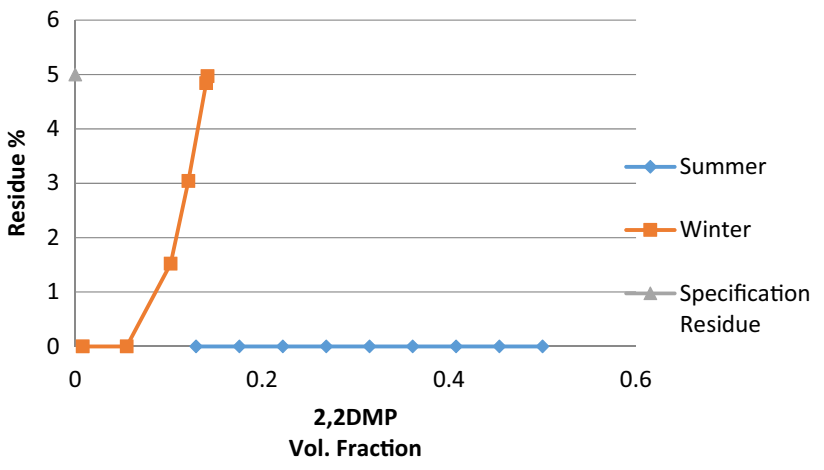

Fig. 13 Limitation of adding 2,2DMP to LPG

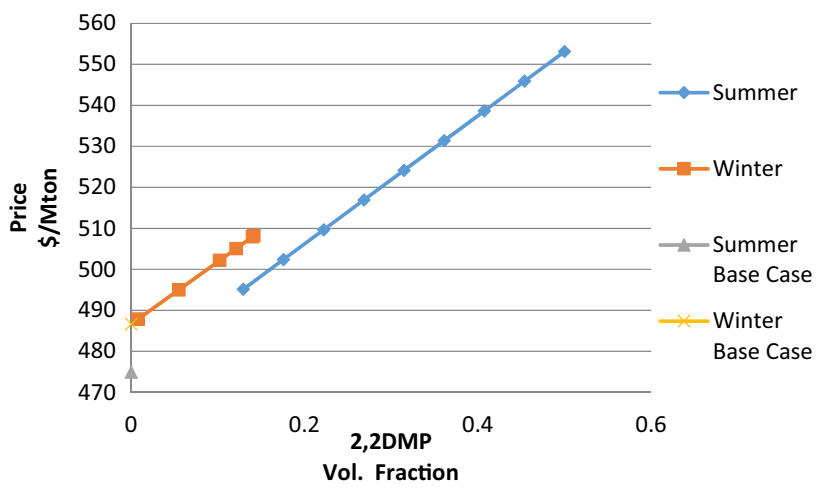

Fig. 14 Effect of adding 2,2DMP on LPG price

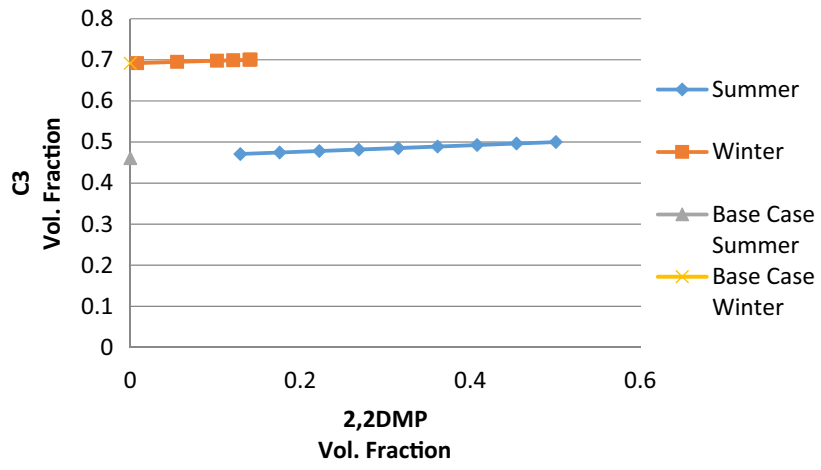

Fig. 15 Effect of adding 2,2DMP on LPG propane content

- Winter case propane increase $=(0.701-0.69175) / 0.691$ $75^{*} 100=1.3 \%$

- Summer case butane saving $=(0.539369-0) /$ $0.539369 * 100=100 \%$

- Winter case butane saving $=(0.30825-0.158) /$ $0.30825 * 100=48.7 \%$ 


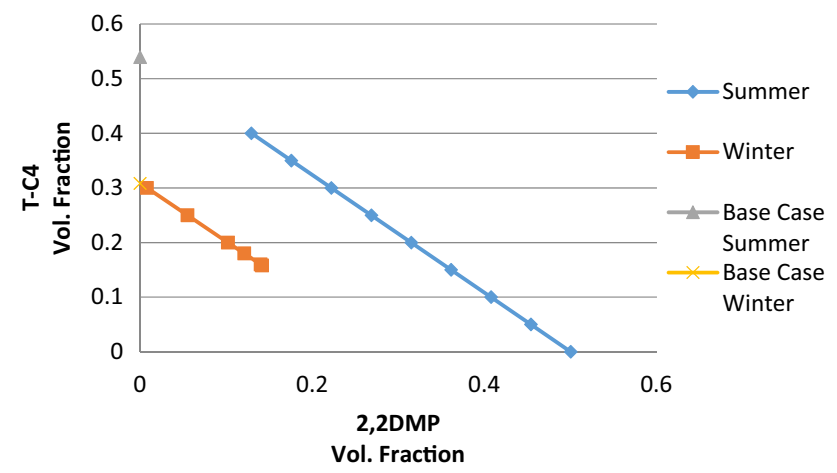

Fig. 16 Effect of adding 2,2DMP on LPG T-C4 content

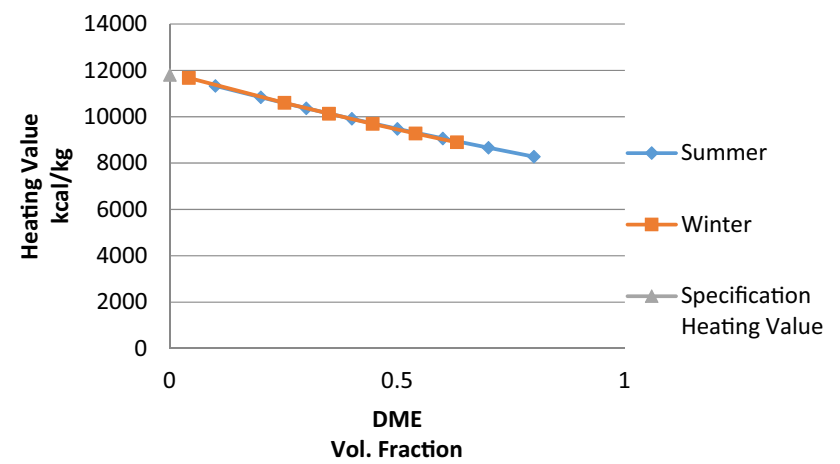

Fig. 17 Effect of adding DME on LPG heating value

\section{Effect of adding DME to LPG}

Adding DME to LPG necessitates the decrease in both propane and butane contents without residue. The limitation of DME addition to LPG is mainly due to heating value as shown in Fig. 17. LPG heating value will be lower than the specified heating value at any content of DME.

Figure 18 illustrates the effect of adding 2,2DMP to LPG price. LPG price increases by $67.6 \%$ in winter and by $87.7 \%$ in summer case.

Propane and butane will be affected by adding DME to LPG as per the following values and Figs. 19 and 20:

- Summer case propane saving $=(0.460631-0.0165) /$ $0.460631 * 100=96 \%$

- Winter case propane saving $=(0.69175-0.369) /$ $0.69175 * 100=46.6 \%$

- Summer case butane saving $=(0.539369-0.1835) /$ $0.539369 * 100=66 \%$

- Winter case butane saving $=(0.30825-0) / 0.30825^{*}$ $100=100 \%$

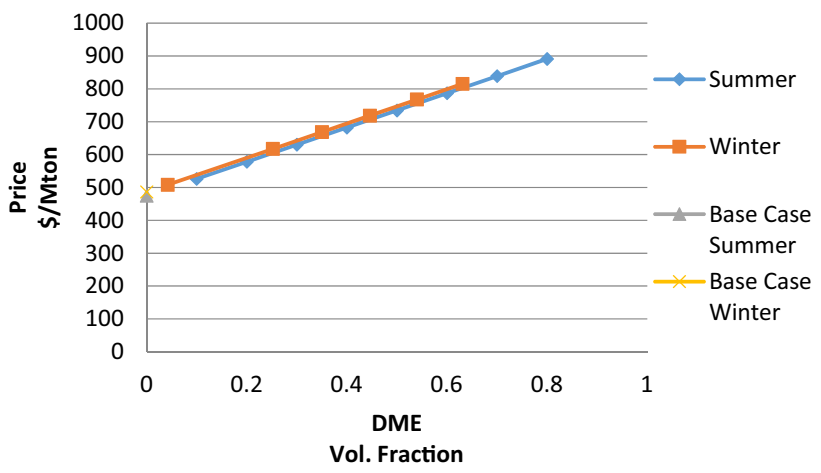

Fig. 18 Effect of adding DME on LPG price

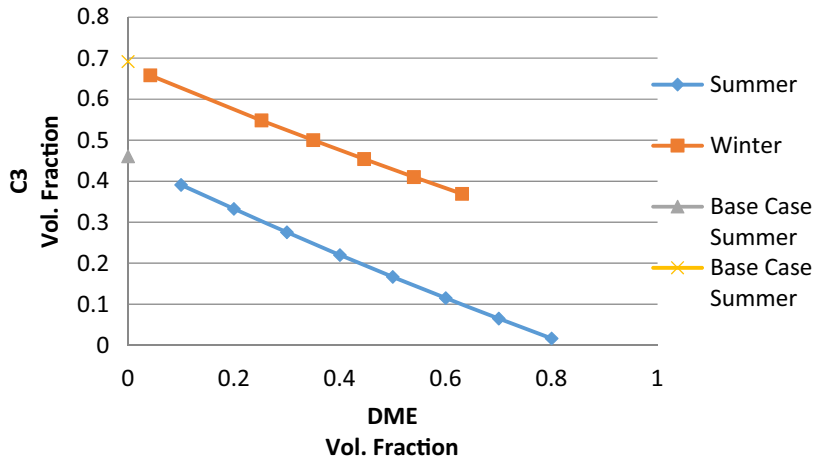

Fig. 19 Effect of adding DME on LPG propane content

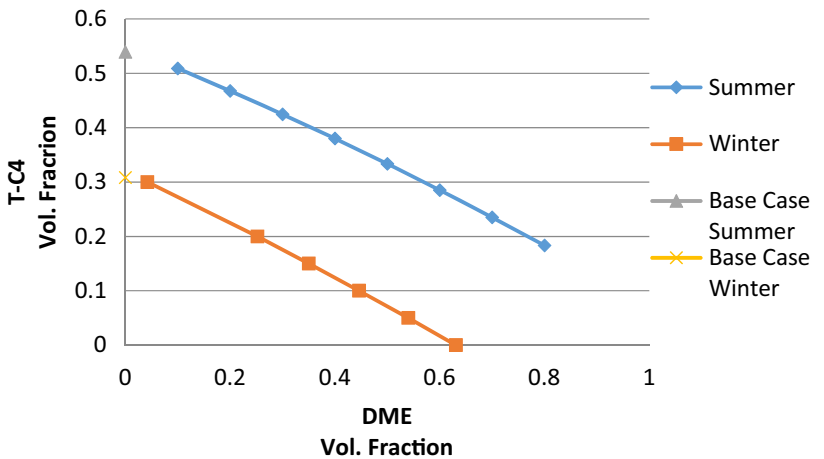

Fig. 20 Effect of adding DME on LPG T-C4 Content

\section{Effect of adding normal pentane ( $n-C 5)$ to LPG}

Adding n-C5 to LPG content is adjusted to get the vapor pressure value of LPG specifications and then the other specifications as LPG residue is measured/recorded from HYSYS dynamic model. Adding $n$-pentane to LPG necessitates the slight increases the propane content, while the butane content has to be decreased. The heating value of LPG by adding $\mathrm{n}-\mathrm{C} 5$ is more than the specifications 


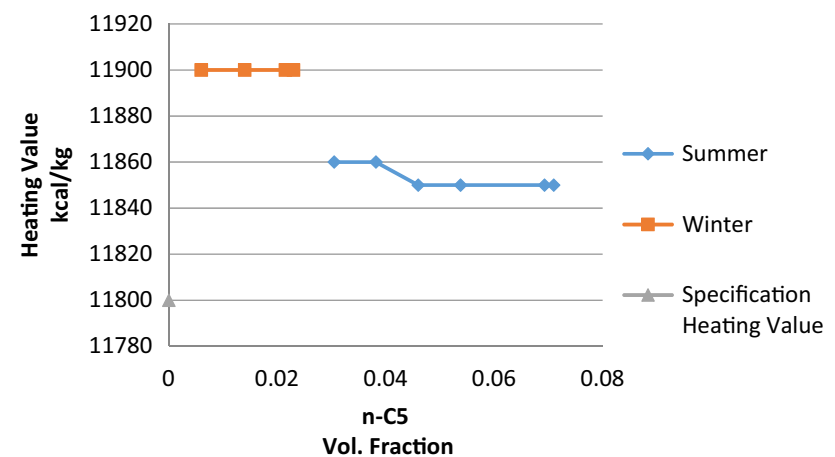

Fig. 21 Effect of adding n-C5 on LPG heating value

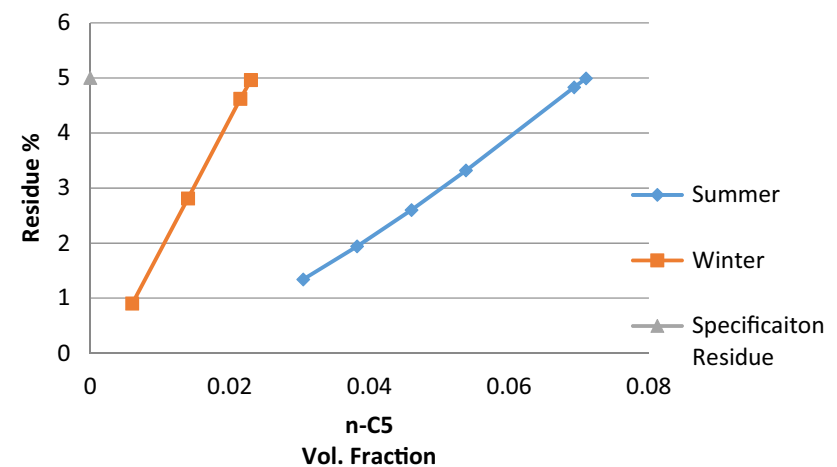

Fig. 22 Limitation of adding n-C5 to LPG

heating value $(11,800 \mathrm{kcal} / \mathrm{kg})$ for both summer and winter cases, as shown in Fig. 21.

Although adding $\mathrm{n}-\mathrm{C} 5$ increases the fuel heating value and requires the decrease in butane content, the limitation to adding $\mathrm{n}-\mathrm{C} 5$ to LPG is due to residue. Higher LPG n-C5 content increases LPG residue. So, to meet the LPG specifications ( $5 \%$ residue), the maximum content of $n-C 5$ inside LPG mixture has to be $7 \mathrm{vol} \%$ in summer and 2.3 vol\% in winter case, as shown in Fig. 22. Increasing n-C5 volume percent violates the specifications percentage.

Figure 23 illustrates the effect of adding n-C5 to LPG price. LPG price in summer case is about $\$ 475 / \mathrm{Mt}$, while in the winter case is about $\$ 486.6 / \mathrm{Mt}$. In case of adding n-C5 to LPG, by the maximum values obtained from Fig. 22, LPG price increases by maximum $0.2 \%$ in winter case and by maximum $0.7 \%$ in summer case.

In case of no added $\mathrm{n}-\mathrm{C} 5$, the propane vol\% is supposed to be $46.06 \%$ in summer case and $69.175 \%$ in the winter case, while the butane vol\% is supposed to be $53.95 \%$ in the summer case and $30.825 \%$ in winter case. For the maximum allowed percent of added $\mathrm{n}-\mathrm{C} 5$, propane and butane will be affected as per the following values and Figs. 24 and 25:

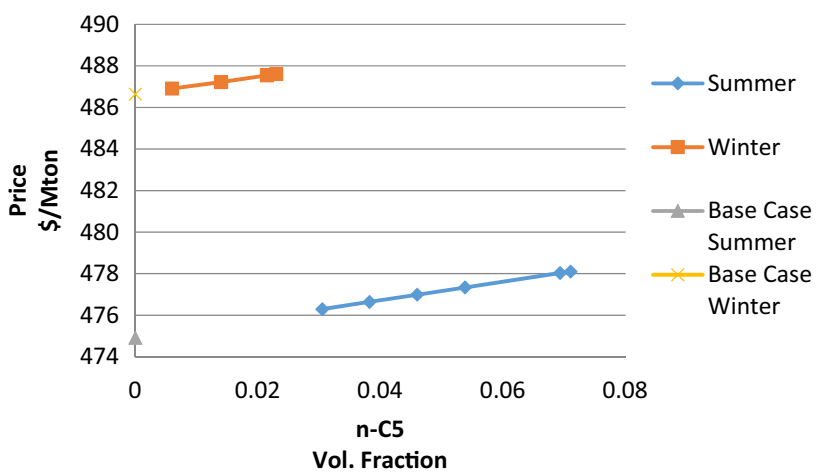

Fig. 23 Effect of adding n-C5 on LPG price

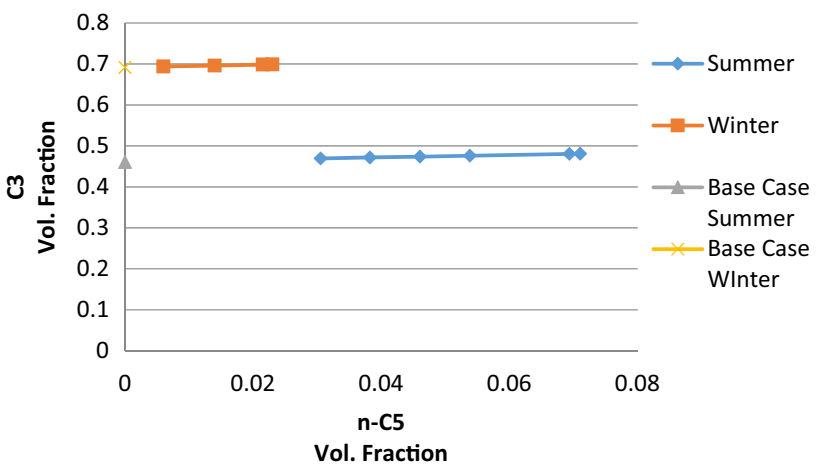

Fig. 24 Effect of adding n-C5 on LPG propane content

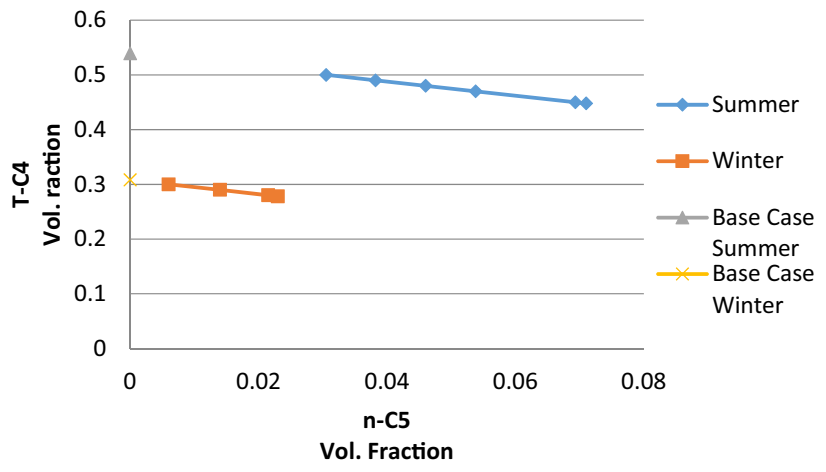

Fig. 25 Effect of adding n-C5 on LPG T-C4 content

- Summer case butane saving $=(0.5395-0.448) /$ $0.5395 * 100=17 \%$

- Winter case butane saving $=(0.30825-0.278) /$ $0.30825 * 100=10 \%$

- Summer case propane increase $=(0.481-0.460631) / 0.4$ $60631 * 100=4.4 \%$

- Winter case propane increase $=(0.699-0.69175) / 0.691$ $75^{*} 100=1 \%$. 


\section{Effect of adding a mixture of 2,2DMP and i-C5 to LPG}

Adding a mixture of 2,2DMP and i-C5 to LPG is adjusted according to the vapor pressure value of LPG specifications and then the other specifications as LPG residue is measured/recorded from HYSYS dynamic model.

To reach the specifications of the fuel vapor pressure, adding a mixture of 2,2DMP and i-C5 to LPG necessitates the slight increase in the propane content, while the butane content has to decreased. Table 8 shows the vol. fraction of 2,2DMP and i-C5 in the LPG mixture. As shown in Table 8, in summer case, starting with $0 \%$ butane, to maintain the specifications of vapor pressure and residue, $9.6 \mathrm{vol} \%$ of i-C5 was added and 39 vol\% of 2,2DMP, while in winter, to maintain the specifications of vapor pressure and residue, 0.7 vol\% of i-C5 was added and $11.33 \mathrm{vol} \%$ of 2,2DMP. Increasing the i-C5 vol\% will necessitate the increase in butane content and the slight decrease in propane and neo-pentane contents.

In winter, the heating value of LPG is more than the specifications at any 2,2DMP and i-C5 content, but there is a limitation to add 2,2DMP and i-C5 to LPG in summer to keep the heating value within acceptable range. Figure 26 shows the limitation of adding 2,2DMP and I-C5 (T-C5 content $34.6 \mathrm{vol} \%$ ) to LPG.

The limitation of 2,2DMP and i-C5 mixture addition to LPG is due to residue. Higher 2,2DMP and i-C5 LPG content increases LPG residue. Thus, to meet the LPG specifications, the maximum content of 2,2DMP and i-C5 mixture inside LPG has to be 48.6 vol\% in summer and $12 \mathrm{vol} \%$ in winter case.

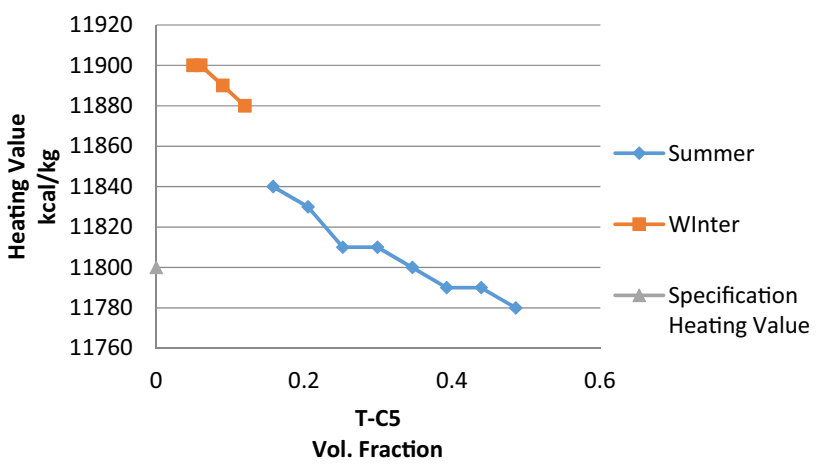

Fig. 26 Effect of adding a mixture of 2,2DMP and i-C5 on LPG heating value

Figure 27 illustrates the effect of adding a mixture of 2,2DMP and i-C5 to LPG price. LPG price increases by $3.6 \%$ in winter case and by $13.7 \%$ in summer case.

Propane and butane will be affected by adding a mixture of 2,2DMP and i-C5 as per the following values and Figs. 28 and 29:

- Summer case butane saving $=(0.5395-0) /$ $0.5395 * 100=100 \%$

- Winter case butane saving $=(0.30825-0.18) /$ $0.30825 * 100=41.5 \%$

- Summer case propane increase $=(0.5142-0.460631) / 0$ $.460631 * 100=11 \%$

- Winter case propane increase $=(0.7-0.69175) / 0.69175$ $* 100=1.2 \%$
Table 8 Volume fraction of 2,2DMP and i-C5 in the LPG mixture

\begin{tabular}{|c|c|c|c|c|c|c|c|c|}
\hline \multirow{2}{*}{$\frac{\text { Vol. fraction }}{\text { Summer }}$} & \multicolumn{8}{|c|}{ i-C5 + 2,2DMP vol. faction in LPG mixture } \\
\hline & & & & & & & & \\
\hline $\mathrm{C} 3$ & 0.514 & 0.511 & 0.507 & 0.504 & 0.501 & 0.498 & 0.495 & 0.492 \\
\hline $\mathrm{i}-\mathrm{C} 4$ & 0 & 0.013 & 0.027 & 0.04 & 0.054 & 0.067 & 0.081 & 0.094 \\
\hline$n-C 4$ & 0 & 0.037 & 0.073 & 0.10 & 0.146 & 0.183 & 0.219 & 0.256 \\
\hline 2,2DMP & 0.390 & 0.342 & 0.293 & 0.24 & 0.193 & 0.143 & 0.092 & 0.04 \\
\hline $\mathrm{i}-\mathrm{C} 5$ & 0.096 & 0.098 & 0.099 & 0.102 & 0.106 & 0.109 & 0.114 & 0.118 \\
\hline Total C5 & 0.486 & 0.439 & 0.393 & 0.346 & 0.299 & 0.252 & 0.205 & 0.158 \\
\hline Total C4 & 0 & 0.05 & 0.1 & 0.15 & 0.2 & 0.25 & 0.3 & 0.35 \\
\hline Winter & & & & & & & & \\
\hline C3 & 0.700 & 0.7 & 0.7 & 0.7 & & & & \\
\hline $\mathrm{i}-\mathrm{C} 4$ & 0.06 & 0.07 & 0.08 & 0.083 & & & & \\
\hline $\mathrm{n}-\mathrm{C} 4$ & 0.12 & 0.14 & 0.16 & 0.167 & & & & \\
\hline 2,2DMP & 0.1133 & 0.0746 & 0.0355 & 0.023 & & & & \\
\hline i-C5 & 0.007 & 0.015 & 0.025 & 0.028 & & & & \\
\hline Total C5 & 0.12 & 0.09 & 0.06 & 0.05 & & & & \\
\hline Total C4 & 0.18 & 0.21 & 0.24 & 0.25 & & & & \\
\hline
\end{tabular}




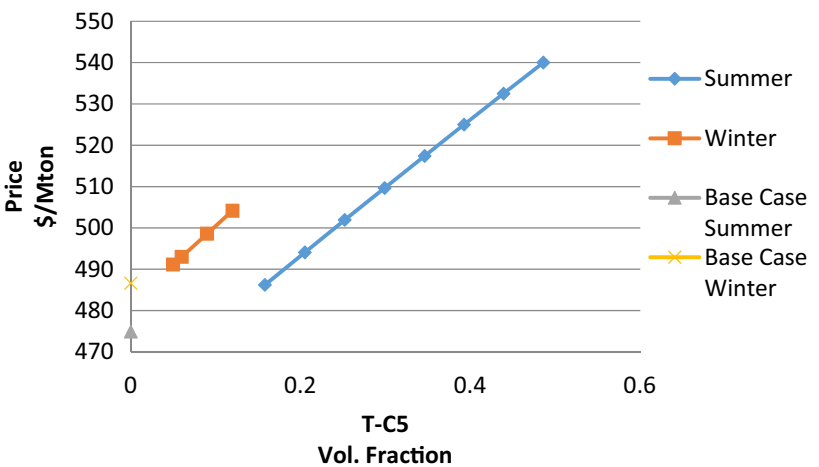

Fig. 27 Effect of adding a mixture of 2,2DMP and i-C5 on LPG price

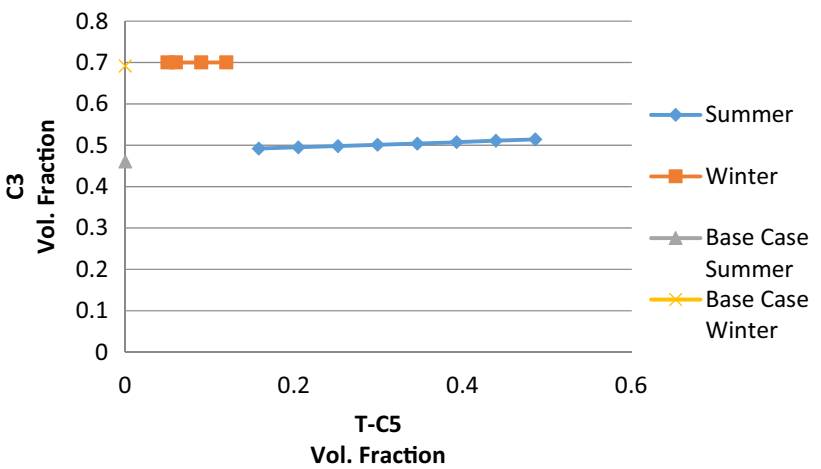

Fig. 28 Effect of adding a mixture of 2,2DMP and i-C5 on LPG propane content

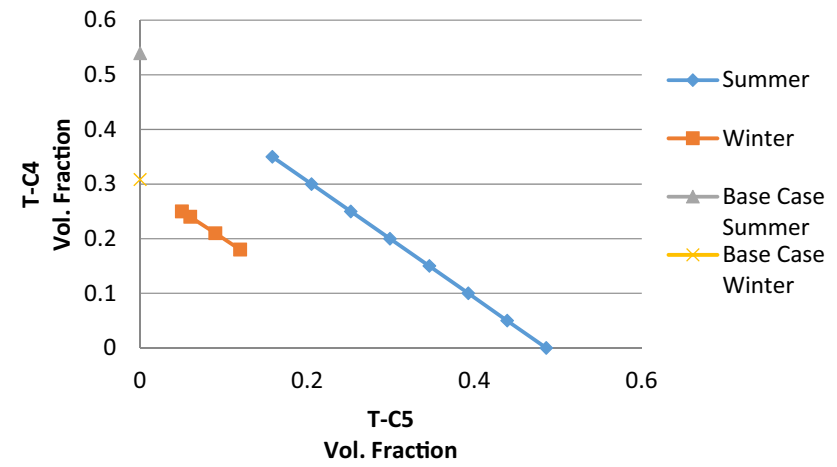

Fig. 29 Effect of adding a mixture of 2,2DMP and i-C5 on LPG T-C4 content

\section{Effect of adding i-C5 and 20 vol\% DME to LPG}

Adding i-C5 and 20 vol\% DME to LPG mixture is adjusted to comply with LPG vapor pressure specifications and then

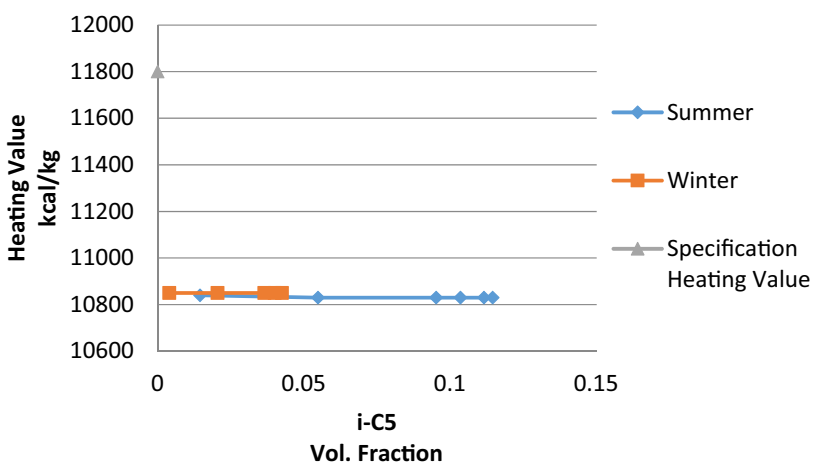

Fig. 30 Effect of adding i-C5 and 20 vol\% DME on LPG heating value

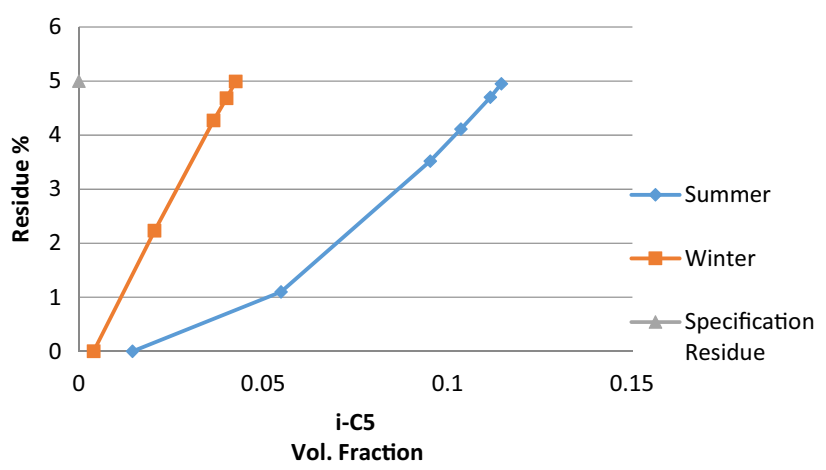

Fig. 31 Limitation of adding i-C5 to 20 vol\% DME and LPG

the other specifications as LPG residue is measured/recorded from HYSYS dynamic model.

As shown in Fig. 30, although the high heating value of i-C5, LPG mixture heating value will be lower than specifications at any content of $\mathrm{i}-\mathrm{C} 5$ in this mixture for both summer and winter cases, due to the very low heating value of DME. It is also worth saying that adding i-C5 to 20 vol\% DME and LPG is better than adding only DME to $\mathrm{LPG}$.

The limitation to add i-C5 and 20 vol\% DME to LPG is due to residue. Higher i-C5 content increases LPG residue. So, to meet the LPG specifications, the maximum content of i-C5 inside 20\% DME-LPG mixture has to be $11.45 \mathrm{vol} \%$ in summer and 4.25 vol\% in winter case as shown in Fig. 31.

Figure 32 illustrates the effect of adding i-C5 and $20 \mathrm{vol} \%$ DME to LPG price. Due to the high price of DME, LPG price increases by $21.6 \%$ in winter case and by $22.7 \%$ in summer case.

Adding i-C5 and 20 vol\% DME to LPG mixture necessitates the decrease in both the propane and butane contents of LPG as per the following values and Figs. 33 and 34: 


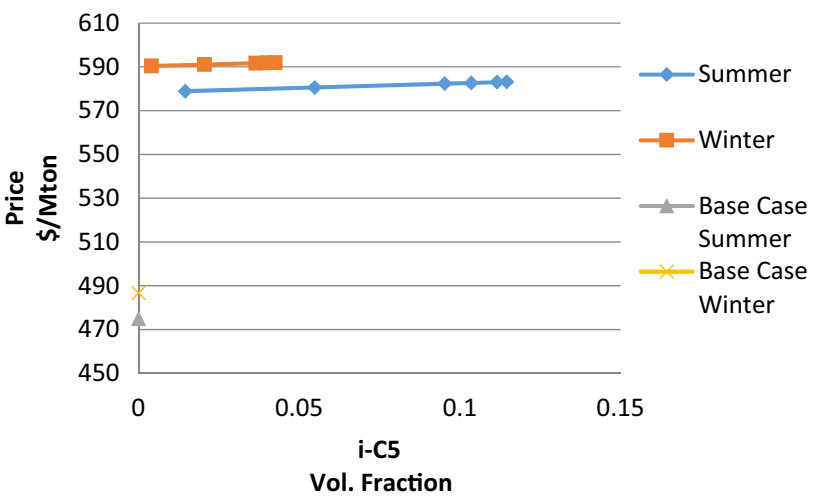

Fig. 32 Effect of adding i-C5 and 20 vol\% DME on LPG price

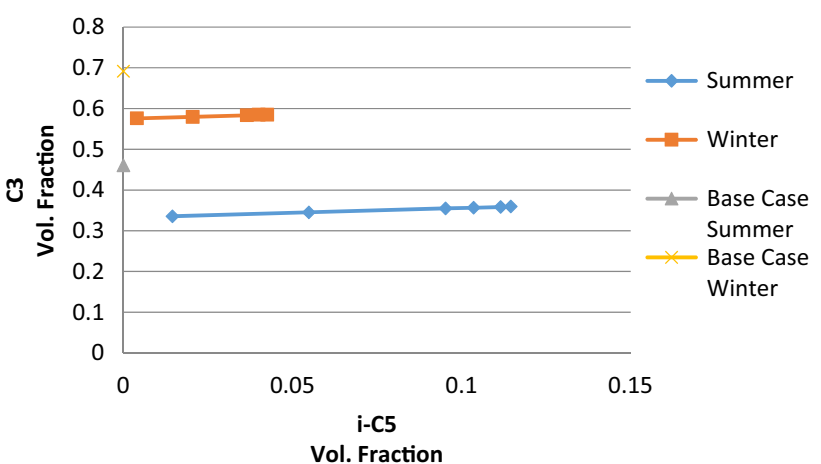

Fig. 33 Effect of adding i-C5 and 20 vol\% DME on LPG propane content

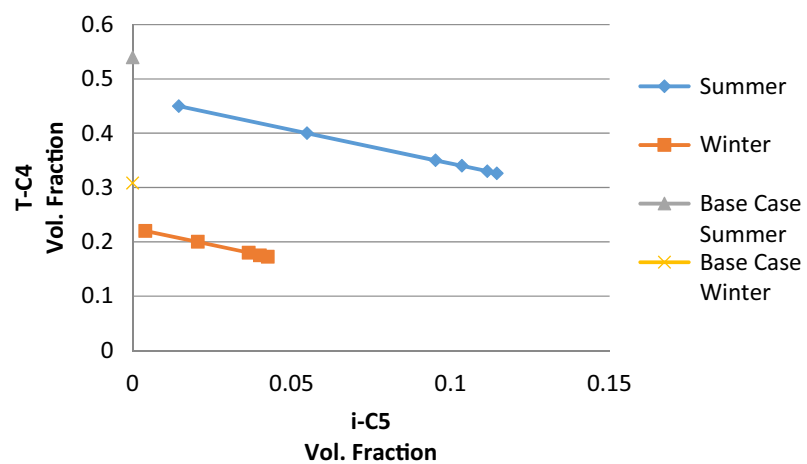

Fig. 34 Effect of adding i-C5 and 20 vol\% DME on LPG T-C4 content

- Summer case butane saving $=(0.5395-0.326) /$ $0.5395 * 100=39.6 \%$

- Winter case butane saving $=(0.30825-0.1725) /$ $0.30825 * 100=44 \%$

- Summer case propane saving $=(0.460631-0.359) /$ $0.460631 * 100=22 \%$

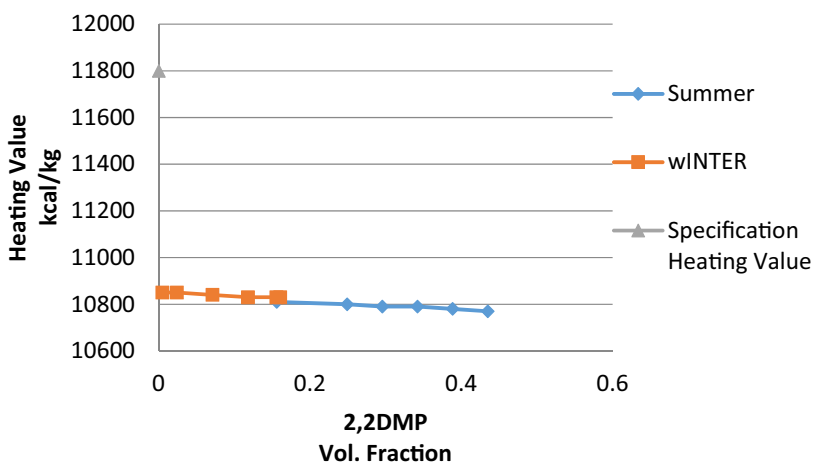

Fig. 35 Effect of adding 2,2DMP and 20 vol\% DME on LPG heating value

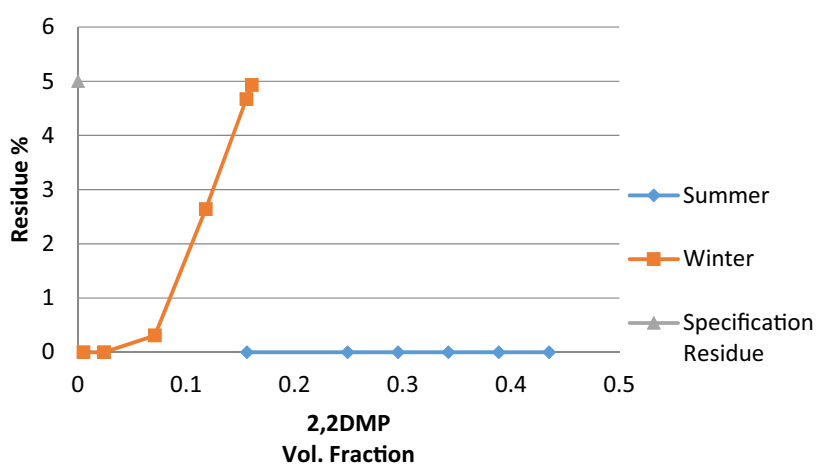

Fig. 36 Limitation of adding 2,2DMP to 20 vol\% DME and LPG

- Winter case propane saving $=(0.69175-0.585) /$ $0.69175 * 100=15.4 \%$.

\section{Effect of adding 2,2DMP and 20 vol\% DME to LPG}

Adding 2,2DMP and 20 vol. \% DME to LPG is adjusted to get the vapor pressure value of LPG specifications and then the other specifications as LPG residue is measured/ recorded from HYSYS dynamic model. Adding mixture of 20 vol. \% DME and 2,2DMP to LPG necessitates the decrease propane and butane content of LPG.

The limitation of adding 2,2DMP to 20 vol. \% DME and LPG is mainly due to heating value as shown in Fig. 35 . LPG heating value will be lower than specifications heating value at any content of 2,2DMP.

There is no residue limitation to add 2,2DMP and 20 vol\% DME to LPG in summer, as for all 2,2DMP volume fractions the residue is below the specifications value, but 2,2DMP could be added by maximum 16.05 vol\% during winter as shown in Fig. 36. 


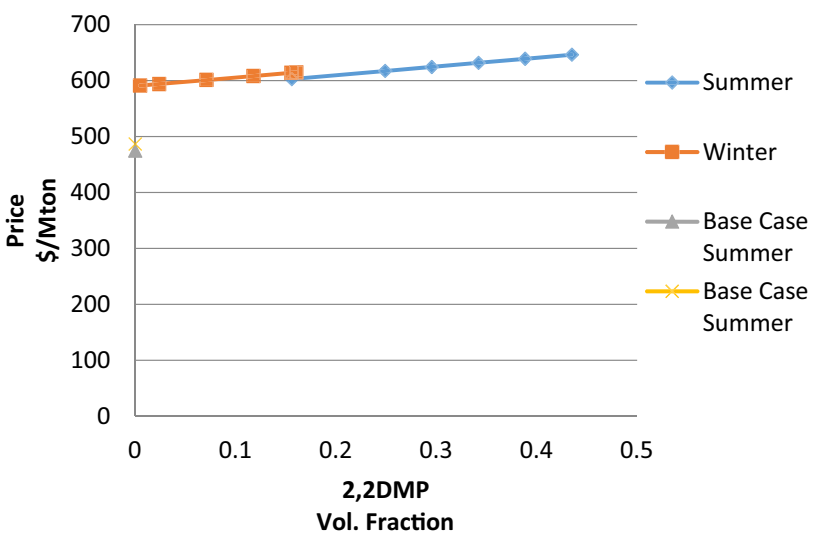

Fig. 37 Effect of adding 2,2DMP and 20 vol\% DME on LPG price

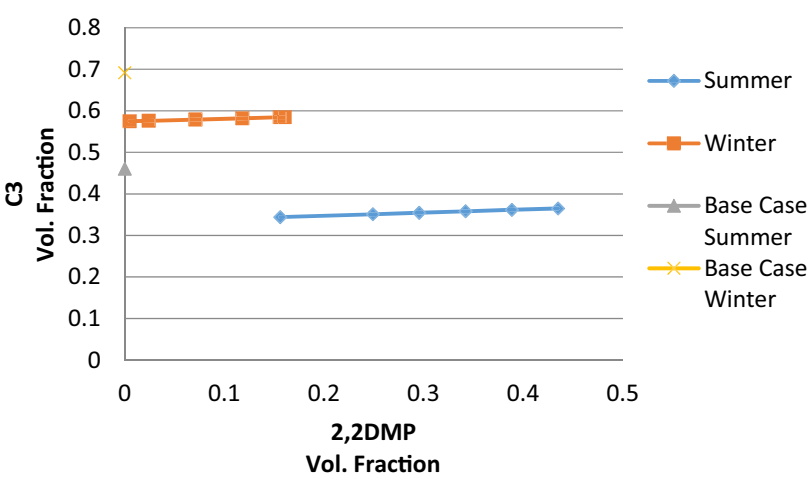

Fig. 38 Effect of adding 2,2DMP and 20 vol\% DME on LPG propane content

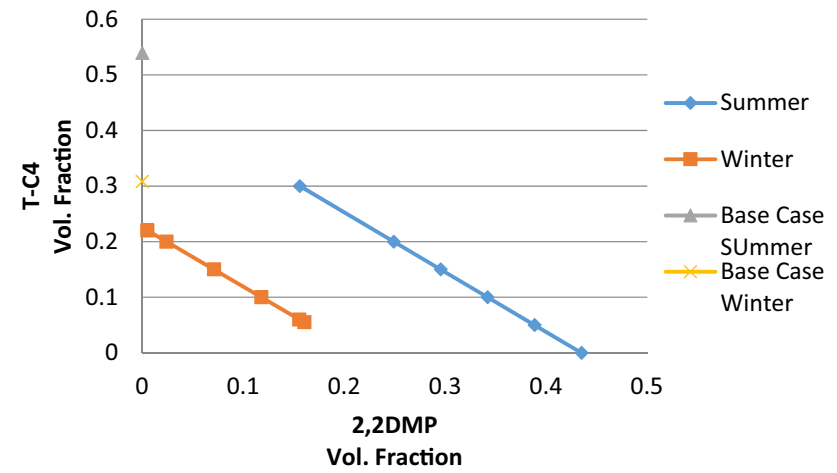

Fig. 39 Effect of adding 2,2DMP and 20 vol\% DME on LPG T-C4 content

Figure 37 illustrates the effect of adding 2,2DMP to 20 vol\% DME and LPG. LPG price increases by $26.3 \%$ in winter case and by $35 \%$ in summer case.
Propane and butane will be affected by adding 2,2DMP to 20 vol\% DME and LPG as per the following values and Figs. 38 and 39:

- Summer case butane saving $=(0.5395-0) /$ $0.5395 * 100=100 \%$

- Winter case butane saving $=(0.30825-0.055) /$ $0.30825 * 100=82.1 \%$

- Summer case propane saving $=(0.460631-0.365) /$ $0.460631 * 100=20.7 \%$

- Winter case propane saving $=(0.69175-0.5845) /$ $0.69175 * 100=15.5 \%$

\section{Effect of adding 2,2DMP, i-C5 and 20 vol\% DME to LPG}

Adding mixture of i-C5 and 2,2DMP and $20 \mathrm{vol} \%$ DME to LPG is adjusted to get the vapor pressure value of LPG specifications and then the other specifications as LPG residue is measured/recorded from HYSYS dynamic model. This will necessitate the decrease in both propane and butane contents of LPG. Table 9 shows the vol. fraction of 2,2DMP and i-C5 in the 20\% DME and LPG mixture.

The limitation of adding i-C5 and 2,2DMP to $20 \mathrm{vol} \%$ DME-LPG mixture is mainly due to heating value, as shown in Fig. 40. LPG heating value will be lower than the specified heating value of LPG at any content of 2,2DMP, i-C5 in the 20 vol\% DME-LPG mixture.

The limitation of adding 2,2DMP, i-C5 to 20 vol\% DMELPG mixture is due to residue. Higher 2,2DMP and i-C5 content increases the LPG residue. So, to meet the LPG specifications, the maximum content of 2,2DMP and i-C5 inside the 20 vol\% DME-LPG mixture has to be $42.2 \mathrm{vol} \%$ in summer and $13.3 \mathrm{vol} \%$ in winter.

Propane and butane will be affected by adding 2,2DMP and i-C5 to 20 vol\% DME and LPG as per the following values and Figs. 41 and 42:

- Summer case butane saving $=(0.5395-0) /$ $0.5395 * 100=100 \%$

- Winter case butane saving $=(0.30825-0.082) /$ $0.30825 * 100=73.4 \%$

- Summer case propane saving $=(0.460631-0.378) /$ $0.460631 * 100=18 \%$

- Winter case propane Saving $=(0.69175-0.585) /$ $0.69175 * 100=15.4 \%$ 
Table 9 Volume fraction of 2,2DMP and i-C5 in the 20 vol\% DME and LPG mixture
i-C5 + 2.2DMP vol. faction in LPG mixture

\begin{tabular}{lllllll}
\hline Summer & & & & & & \\
2,2DMP & 0.3333 & 0.2837 & 0.234 & 0.1835 & 0.1318 & 0.0273 \\
i-C5 & 0.0885 & 0.0911 & 0.094 & 0.0975 & 0.102 & 0.112 \\
Winter & & & & & \\
2,2DMP & 0.123 & 0.0985 & 0.0305 & 0.013 & \\
i-C5 & 0.01 & 0.0165 & 0.0345 & 0.039 & & \\
\hline
\end{tabular}

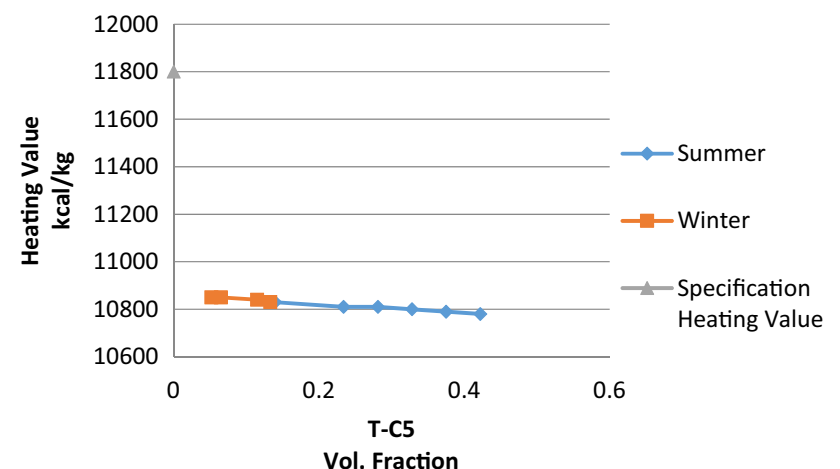

Fig. 40 Effect of adding i-C5, 2,2DMP and 20 vol\% DME on LPG heating value

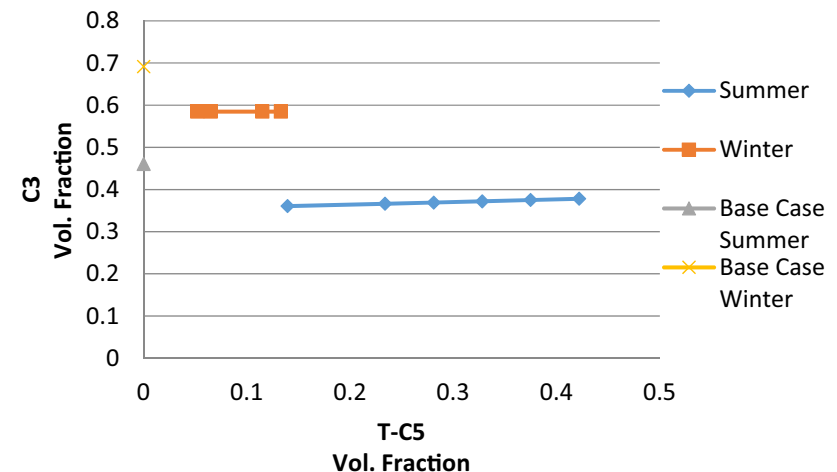

Fig. 41 Effect of adding i-C5, 2,2DMP and 20 vol\% DME on LPG propane content

Figure 43 illustrates the effect of adding 2,2DMP and i-C5 to $20 \mathrm{vol} \%$ DME and LPG on price. LPG price increases by $25 \%$ in winter case and by $33 \%$ in summer case.

\section{Neo-pentane production}

Neo-pentane can be produced by mixing treated naphtha with recycle streams and heating up to $139{ }^{\circ} \mathrm{C}$ and then introducing this mixture into the isomerization reactor.

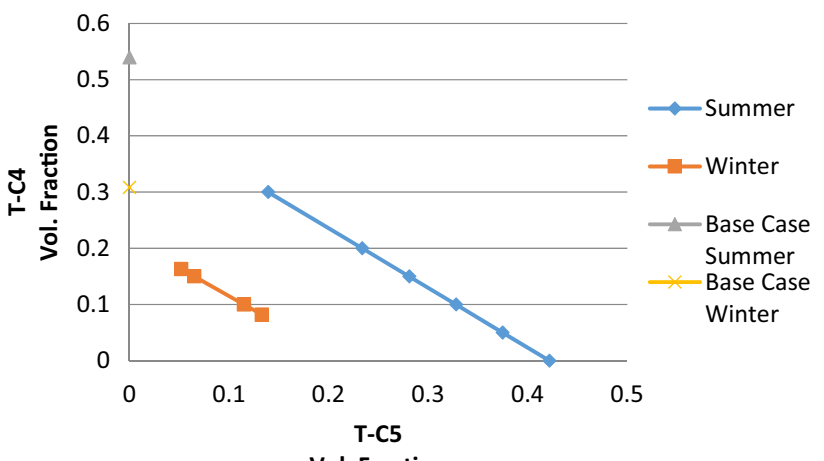

Vol. Fraction

Fig. 42 Effect of adding i-C5, 2,2DMP and 20 vol\% DME on LPG T-C4 content

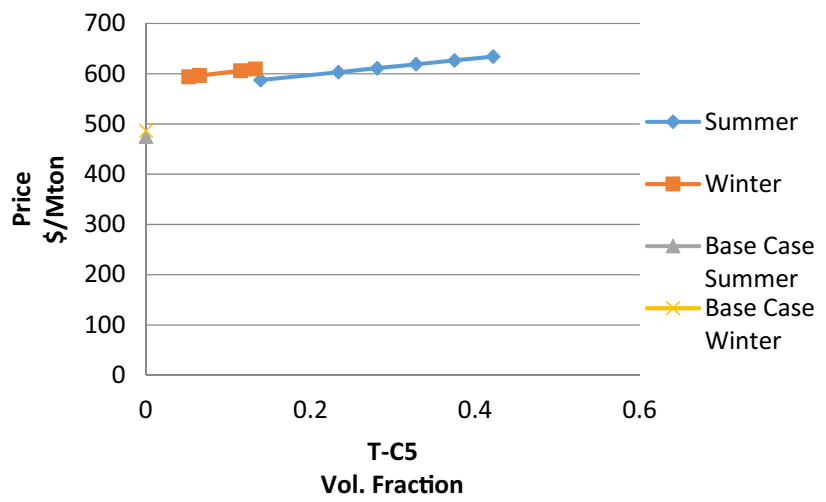

Fig. 43 Effect of adding i-C5, 2,2DMP and 20 vol\% DME on LPG price

The reactor products are then introduced into depentanizer to get stabilized gasoline from the bottom, and overhead vapor is further separated in the deethanizer tower to remove ethane, lighter hydrocarbons and hydrogen. Deethanizer bottom product is introduced into deisopentanizer tower to separate normal pentane from iso-pentane. The $n$-pentane is recycled for further conversion. The overhead product of deisopentanizer is sent to deneopentanizer to separate the iso-pentane and neo-pentane. Table 10 shows the composition and the operating conditions of isomerization unit inlet feed. Table 11 shows the optimum tower operating 
Table 10 Isomerization feed composition and isomerization inlet feed operating condition

\begin{tabular}{ll}
\hline Component & Composition \\
\hline Hydrogen & 0 \\
Methane & 0 \\
Ethane & 0 \\
Propane & 0 \\
i-Butane & 0.001 \\
$n$-Butane & 0.012 \\
22-Mpropane & 0 \\
i-Pentane & 0.168 \\
$n$-Pentane & 0.280 \\
22-Mbutane & 0.003 \\
23-Mbutane & 0 \\
2-Mpentane & 0 \\
3-Mpentane & 0.098 \\
$n$-Hexane & 0.260 \\
Cyclopentane & 0.042 \\
Mcyclopentane & 0.062 \\
Benzene & 0.018 \\
Cyclohexane & 0.034 \\
$n$-Heptane & 0.023 \\
Nitrogen & 0 \\
$\mathrm{H}_{2} \mathrm{O}$ & 0 \\
Inlet feed operating gauge pressure $\left(\mathrm{kg}_{\mathrm{f}} / \mathrm{cm}^{2}\right)$ & 36.6 \\
Inlet feed temperature $\left({ }^{\circ} \mathrm{C}\right)$ & 45 \\
\hline
\end{tabular}

conditions and design parameters. Figure 44 illustrates the process flow sheet of neo-pentane production.

\section{Conclusion}

Adding ethane to LPG necessitates the increase in the butane content and the decrease in the propane content. Due to ethane critical properties, it is not recommended to add ethane in LPG, as it may separate inside the LPG bottle.

On the other hand, adding i-C5, 2,2DMP or n-C5 to LPG necessitates the decrease in the butane content and a slight increase in the propane content. Meanwhile adding DME to LPG necessitates the decrease of both the butane and propane content of LPG. Accordingly, it is recommended to utilize mixture of DME with $\mathrm{C} 5$ isomers to decrease the butane and propane content of LPG.

\section{Minimum butane content}

The following proposed LPG mixtures provide the minimum butane content:

In summer $(0 \%)$ :

- 50 vol\% 2,2DMP

- 20 vol\% of DME with 43.5 vol\% 2,2DMP

- 9.6 vol\% of i-C5 with 39.1 vol\% 2,2DMP

- 20 vol\% of DME, 8.9 vol\% i-C5 with 33.3 vol\% 2,2DMP.

In winter $(0 \%)$ :

- 63 vol\% DME

\section{Maximum butane content}

The following proposed LPG mixtures provide the maximum butane content:

In summer (70\%):

- 5 vol\% Ethane

In winter (47\%):

- 5 vol\% Ethane

\section{Minimum propane content}

The following proposed LPG mixtures provide the minimum propane content:

In summer $(0.02 \%)$ :

- 80 vol\% DME

In winter (37\%):

Table 11 Towers process input data

\begin{tabular}{lllllll}
\hline Service & $\begin{array}{l}\text { Operating pressure, } \\
\text { gauge }\left(\mathrm{kg}_{\mathrm{f}} / \mathrm{cm}^{2}\right)\end{array}$ & $\begin{array}{l}\text { Operating temperature } \\
\text { top/bottom }\left({ }^{\circ} \mathrm{C}\right)\end{array}$ & $\begin{array}{l}\text { Number of } \\
\text { trays }\end{array}$ & Reflux Ratio & $\begin{array}{l}\text { OVHD cooler } \\
\text { duty }(\mathrm{kJ} / \mathrm{h})\end{array}$ & $\begin{array}{l}\text { Bottom } \\
\text { reboiler duty } \\
(\mathrm{kJ} / \mathrm{h})\end{array}$ \\
\hline Gasoline stabilizer & 29.5 & $175 / 217$ & 30 & - & - & $2.2 \times 10^{7}$ \\
De-ethanizer & 21 & $128 / 166$ & 15 & Total Reflux & $7.5 \times 10^{6}$ & $2.9 \times 10^{6}$ \\
De-isopentanizer & 0.8 & $41.1 / 72$ & 50 & 4.3 & $2.1 \times 10^{7}$ & $1.36 \times 10^{7}$ \\
De-neopentanizer & 5 & $81.7 / 95$ & 50 & 1 & $4 \times 10^{6}$ & $5.4 \times 10^{6}$ \\
\hline
\end{tabular}




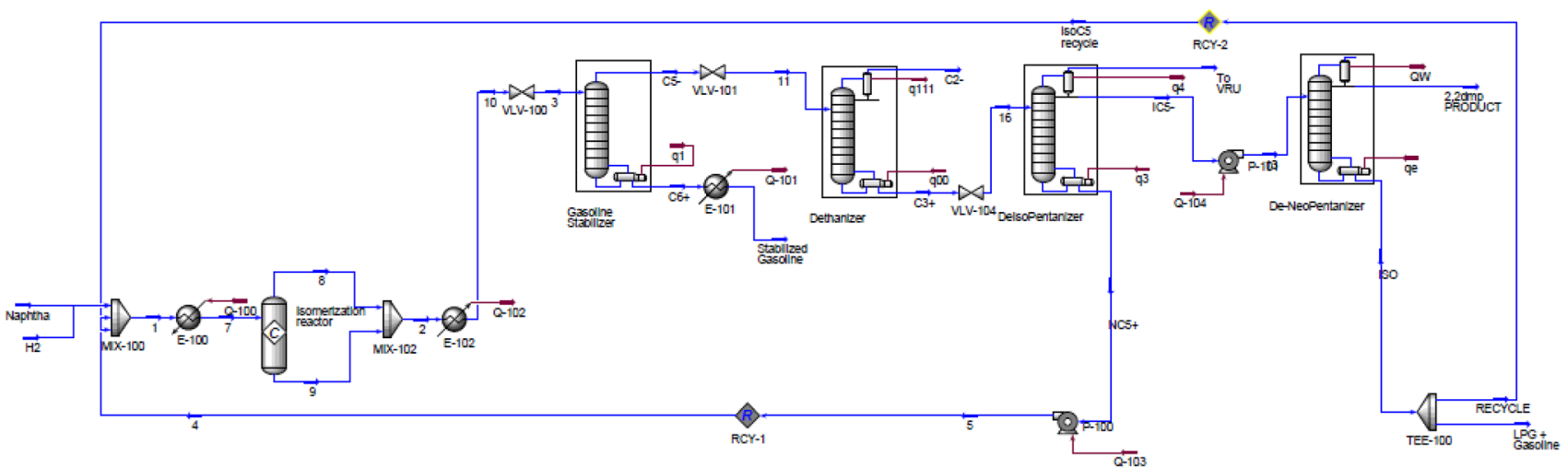

Fig. 44 Process flow sheet of neo-pentane production

- 63 vol\% DME

\section{Maximum propane content}

The following proposed LPG mixtures provide the maximum propane content:

In summer (51.4\%):

- 9.6 vol\% i-C5 with 39 vol\% 2,2DMP

In winter $(70 \%)$ :

- 14.2 vol\% 2,2DMP

\section{Maximum heating value}

The following proposed LPG mixtures provide the maximum heating value:

In summer $(11,860 \mathrm{kcal} / \mathrm{kg})$ :

- 3 vol\% n-C5

In winter $(11,900 \mathrm{kcal} / \mathrm{kg})$ :

- $\mathrm{i}-\mathrm{C} 5$

- $\mathrm{n}-\mathrm{C} 5$

- 0.8 vol\% 2,2DMP

- $0-2$ vol. \% of Ethane

- 2.5 vol. \% i-C5 with 3.6 vol\% 2,2DMP

\section{Minimum heating value}

The following proposed LPG mixtures provide the minimum heating value:

In summer $(8274 \mathrm{kcal} / \mathrm{kg})$ :

- $80 \%$ vol $\%$ DME
In winter $(8892 \mathrm{kcal} / \mathrm{kg})$ :

- 63 vol\% DME

\section{Minimum LPG cost}

The following proposed LPG mixtures provide the minimum LPG cost:

In summer $(\$ 453 / \mathrm{Mt})$ :

- 5 vol\% Ethane

In winter $(\$ 892 / \mathrm{Mt})$ :

- 80 vol\% DME

\section{Maximum LPG cost}

The following proposed LPG mixtures provide the maximum LPG cost:

In summer $(\$ 465 / \mathrm{Mt})$ :

- 5 vol\%. Ethane

In winter $(\$ 892 / \mathrm{Mt})$ :

- 63 vol\% DME

From the above results, it is obvious that adding neo-pentane to LPG is the optimum choice for the following reasons:

- Butane content is saved by $100 \%$ in summer and $48.7 \%$ in winter.

- For any neo-pentane content, there are no residue limitations in summer cases 
- For any neo-pentane content, LPG heating value is always above the specifications in winter.

- The LPG price will be increased by $4.4 \%$ in winter and $16.5 \%$ in summer. This could be enhanced if neo-pentane has been available in the market, using the above neopentane modified isomerization unit.

Open Access This article is licensed under a Creative Commons Attribution 4.0 International License, which permits use, sharing, adaptation, distribution and reproduction in any medium or format, as long as you give appropriate credit to the original author(s) and the source, provide a link to the Creative Commons licence, and indicate if changes were made. The images or other third party material in this article are included in the article's Creative Commons licence, unless indicated otherwise in a credit line to the material. If material is not included in the article's Creative Commons licence and your intended use is not permitted by statutory regulation or exceeds the permitted use, you will need to obtain permission directly from the copyright holder. To view a copy of this licence, visit http://creativecommons.org/licenses/by/4.0/.

\section{References}

Ammar S, Khalifa F(2013) LPG plant revamp to increase capacity, produce commercial-grade propane. Gas Processing \& LNG. Technology and Business Information for the Global Gas Processing Industry

Anggarania R, WibowoaCS, RuliantoaD (2014) Application of dimethyl ether as LPG substitution for household stove. In: Conference and exhibition indonesia renewable energy \& energy conservation [Indonesia EBTKE CONEX 2013]

Argus White Paper: Statistical Review of Global LPG.2020

Bahmani M, Shariati J, Rouzbahani AN (2017) Simulation and optimization of an industrial gas condensate stabilization unit to modify LPG and NGL production with minimizing $\mathrm{CO}_{2}$ emission to the environment. Chin J Chem Eng 25:338-346

Bhran A, Hassanean MH, Helal MG (2015) Maximization of natural gas liquids production from an existing gas plant. Egypt J Pet Egypt Pet Res Inst 25:333-341

Bilal AA, Said SA (2003) Assessment of LPG as a possible alternative to R-12 in domestic refrigerators. Energy Convers Manag 44:381-388

Clifford EA (1973) Practical guide to LP-gas utilisation review. Moore Company Ltd, New York, pp 8-59

Chang HR, Reid RC (1982) Spreading-boiling model for instantaneous spills of LPG on waters. J Hazard Mater 7:19-35

Diaz L, Schifter I, Lopez-Salinas E, Gamas E, Rodriguez R, Avalos A (2000) Optimizing automotive LPG blend for Mexico City. Fuel 79:79-88

Egyptian Central Agency for Public Mobilization and Statistics (2020)

Egyptian Organization for Standards \& Quality. https://www.eos.org. eg/en

Global Partnership for Social Accountability (GPSA) 2020. https:// www.thegpsa.org/

Jaimes L, Sandoval J (2002) Propane and butane emission sources to ambient air of Mexico City metropolitan area. Sci Total Environ 289:243-247
Johnson RD (1977) The outlook for LPG 1977-1985. EIU special report no. 44. London: The Economist Intelligence Unit Ltd., pp 3-42

Lemoff TC (1989) Liquefied petroleum gases handbook, 2nd edn. National Fire Protection Association, Massachusetts, pp 5-35

Liang B, Balasubramanian S, Wang B, Yang A, Kennedy D, Le V, Legaspi J, Southern J (2010) LPG characterization and production quantification for oil and gas reservoirs. J Nat Gas Sci Eng 2:244-252

Liu K, Zhang BJ, Chen QL (2015) A new absorption process to intensify liquefied petroleum gas recovery from raw natural gas. Energy Procedia 75:853-859

Martyr AJ, Plint MA (2012) Fuel and oil storage, supply and treatment. Chapter 8, Engine Testing (Fourth Edition), pp.83-201.

Stawczyk J (2003) Experimental evaluation of LPG tank explosion hazards. J Hazard Mater 39:189-200

WLPGA Annual Report (2020)

Wooley RL (1980) Method and apparatus for providing increased thermal conductivity and heat capacity to a pressure vessel containing a hydrite-forming metal material. US Patent No. 4187092

Yaws CL (2015) The Yaws handbook of vapor pressure: antoine coefficients. Gulf Professional Publishing, New York

Yue WS (1999) Kajian Kecekapan Pemindahan Haba Dalam Storan Gas Petroleum Cecair. Universiti Teknologi Malaysia: Tesis Sarjana Muda

Zakaria Z, Mustafa A (2011) The influence of compositions on liquefied petroleum gas residue in storage. Int J Recent Res Appl Stud 7:360-367

Zakaria, ZB, Mustafa A, Mat H (2006) Heat and mass transfer studies in liquefied petroleum gas storage operations. Universiti Teknologi Malaysia.

\section{Websites}

1. https://www.icis.com/resources/news/2018/01/12/10182794/usethane-hits-13-month-high-on-strong-demand-rising-natgas-price s/

2. https://ycharts.com/indicators/mont_belvieu_propane_spot_price

3. https://www.kallanishenergy.com/2018/01/10/ngl-prices-weaken-inlatest-pira-survey

4. https://www.globalpetrolprices.com/gasoline_prices/

5. https://report.basf.com/2017/en/managements-report/basf-group -business-year/economic-environment/important-raw-materials. html

6. https://www.alibaba.com/product-detail/Competitive-dimethylether-prices_1513621496.html?spm=a2700.7724857.main0 7.41.61961c90X8iUK9)

7. https://www.methanex.com/our-business/pricing

8. https://www.platts.com/methodology-specifications-details/conve rsion

Publisher's Note Springer Nature remains neutral with regard to jurisdictional claims in published maps and institutional affiliations. 